\title{
The Drone Revolution of Shark Science: A Review
}

\author{
Paul A. Butcher 1,2,*iD, Andrew P. Colefax ${ }^{3}$, Robert A. Gorkin III ${ }^{4} \mathbb{D}$, Stephen M. Kajiura ${ }^{5}$, Naima A. López ${ }^{6} \mathbb{D}$, \\ Johann Mourier ${ }^{7}$ (D), Cormac R. Purcell ${ }^{8,9}{ }^{\mathbb{D}}$, Gregory B. Skomal ${ }^{10}$, James P. Tucker ${ }^{2}$, Andrew J. Walsh ${ }^{3,8}$, \\ Jane E. Williamson ${ }^{11}\left(\mathbb{D}\right.$ and Vincent Raoult ${ }^{12}$ (D)
}

check for updates

Citation: Butcher, P.A.; Colefax, A.P.; Gorkin, R.A., III; Kajiura, S.M.; López, N.A.; Mourier, J.; Purcell, C.R.;

Skomal, G.B.; Tucker, J.P.; Walsh, A.J.; et al. The Drone Revolution of Shark Science: A Review. Drones 2021, 5, 8. https://doi.org/10.3390/ drones5010008

Received: 26 November 2020

Accepted: 14 January 2021

Published: 21 January 2021

Publisher's Note: MDPI stays neutral with regard to jurisdictional claims in published maps and institutional affiliations.

Copyright: (c) 2021 by the authors. Licensee MDPI, Basel, Switzerland. This article is an open access article distributed under the terms and conditions of the Creative Commons Attribution (CC BY) license (https:/ / creativecommons.org/licenses/by/ $4.0 /)$.
1 NSW Department of Primary Industries, National Marine Science Centre, P.O. Box 4321, Coffs Harbour, NSW 2450, Australia

2 School of Environment, Science and Engineering, Southern Cross University, National Marine Science Centre, Coffs Harbour, NSW 2450, Australia; j.tucker.22@student.scu.edu.au

3 Sci-eye, P.O. Box 4202, Goonellabah, NSW 2480, Australia; acolefax@scieye.com.au (A.P.C.); awalsh@scieye.com.au (A.J.W.)

4 SMART Infrastructure Facility, University of Wollongong, Wollongong, NSW 2522, Australia; rgorkin@uow.edu.au

5 Department of Biological Sciences, Florida Atlantic University, Boca Raton, FL 33431, USA; kajiura@fau.edu

6 Marine Futures Lab, School of Biological Sciences, University of Western Australia, Crawley, WA 6009, Australia; naima.lopez@research.uwa.edu.au

7 UMS 3514 Plateforme Marine Stella Mare, Université de Corse Pasquale Paoli, 20620 Biguglia, France; MOURIER_@@univ-corse.fr

8 Department of Physics and Astronomy, Faculty of Science and Engineering, Macquarie University, Sydney, NSW 2109, Australia; cormac.purcell@mq.edu.au

9 Sydney Institute for Astronomy (SIfA), School of Physics, The University of Sydney, Sydney, NSW 2006, Australia

10 Massachusetts Division of Marine Fisheries, 836 South Rodney French Blvd., New Bedford, MA 02744, USA; gregory.skomal@state.ma.us

11 Marine Ecology Group, Department of Biological Sciences, Macquarie University, Sydney, NSW 2109, Australia; jane.williamson@mq.edu.au

12 School of Environmental and Life Sciences, University of Newcastle, Ourimbah, NSW 2258, Australia; vincent.raoult@newcastle.edu.au

* Correspondence: paul.butcher@dpi.nsw.gov.au

Abstract: Over the past decade, drones have become a popular tool for wildlife management and research. Drones have shown significant value for animals that were often difficult or dangerous to study using traditional survey methods. In the past five years drone technology has become commonplace for shark research with their use above, and more recently, below the water helping to minimise knowledge gaps about these cryptic species. Drones have enhanced our understanding of shark behaviour and are critically important tools, not only due to the importance and conservation of the animals in the ecosystem, but to also help minimise dangerous encounters with humans. To provide some guidance for their future use in relation to sharks, this review provides an overview of how drones are currently used with critical context for shark monitoring. We show how drones have been used to fill knowledge gaps around fundamental shark behaviours or movements, social interactions, and predation across multiple species and scenarios. We further detail the advancement in technology across sensors, automation, and artificial intelligence that are improving our abilities in data collection and analysis and opening opportunities for shark-related beach safety. An investigation of the shark-based research potential for underwater drones (ROV/AUV) is also provided. Finally, this review provides baseline observations that have been pioneered for shark research and recommendations for how drones might be used to enhance our knowledge in the future.

Keywords: artificial intelligence; AUV; drones; protocols; ROV; sharks; UAV 


\section{Overview}

Drones, the common term for unmanned aerial vehicles (UAVs) [1], have become a fundamental tool for the shark researcher. The rapid proliferation of the technology as well as the advancement in visualization capabilities, coupled with increasing cost effectiveness, have enabled new studies for all types of marine-based observations globally [2], particularly in the field of shark research (Figure 1, Table 1).

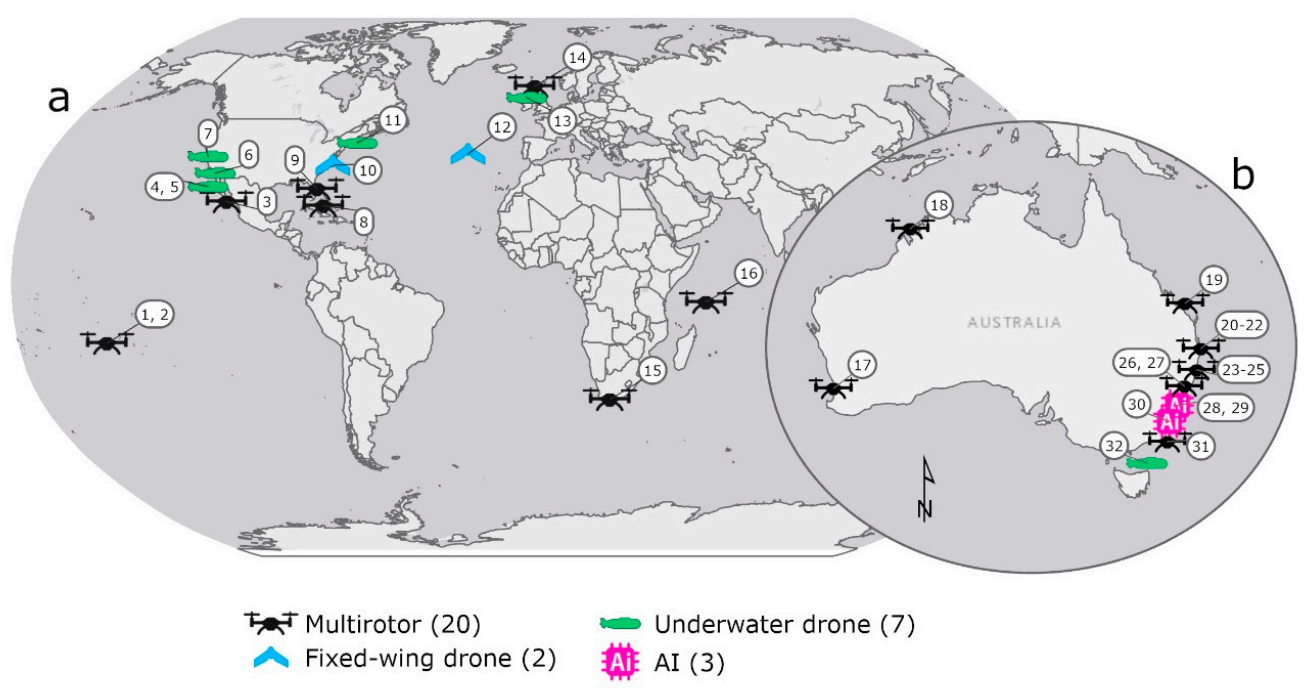

Figure 1. Global representation of research groups using drones for shark research with (a) representation of 32 studies (see Table 1) conducted with different drone systems, and (b) amplified view of Australia, which per continent (and obviously surrounded by water and many shark species) has potentially the most extensive use of drones and shark research globally.

Table 1. Location, drone (type and model) and research focus for studies working on shark drone projects. ID codes correspond to numbers in Figure 1.

\begin{tabular}{|c|c|c|c|c|c|}
\hline ID & Location & Drone & Model & Focus & Reference \\
\hline 1 & $\begin{array}{c}\text { Moorea, French } \\
\text { Polynesia }\end{array}$ & Multirotor & DJI Phantom 2 & Shark density & Kiszka et al. [3] \\
\hline 2 & $\begin{array}{l}\text { Moorea, French } \\
\text { Polynesia }\end{array}$ & Multirotor & DJI Phantom 2 & Shoaling behaviour & Rieucau et al. [4] \\
\hline 3 & $\begin{array}{c}\text { Bahia de la Paz, } \\
\text { Baja, Mexico }\end{array}$ & Multirotor & DJI Spark & Co-occurrence & Frixione et al. [5] \\
\hline 4 & $\begin{array}{l}\text { Guadalupe Island, } \\
\text { Mexico }\end{array}$ & $\begin{array}{l}\text { Underwater drone } \\
\text { (AUV) }\end{array}$ & REMUS-100 & Shark behaviour & Skomal et al. [6] \\
\hline 5 & $\begin{array}{c}\text { Guadalupe Island, } \\
\text { Mexico }\end{array}$ & $\begin{array}{l}\text { Underwater drone } \\
\text { (AUV) }\end{array}$ & REMUS-100 & Fine scale movements & Gabriel [7] \\
\hline 6 & La Jolla, CA, USA & $\begin{array}{l}\text { Underwater drone } \\
\text { (AUV) }\end{array}$ & Not-specified & Group movements & Ho et al. [8] \\
\hline 7 & $\begin{array}{l}\text { SeaPlane Lagoon, } \\
\text { CA, USA }\end{array}$ & $\begin{array}{l}\text { Underwater drone } \\
\text { (AUV) }\end{array}$ & Oceanserver IVER2 & Shark movements & Clark et al. [9] \\
\hline 8 & Bahamas, USA & Multirotor & DJI Phantom 2+ & Detectability & Hensel et al. [10] \\
\hline 9 & $\begin{array}{c}\text { Florida SE Coast, } \\
\text { USA }\end{array}$ & Multirotor & DJI Phantom 4 Pro & $\begin{array}{c}\text { Predatory avoidance } \\
\text { behaviour }\end{array}$ & Doan and Kajiura [11] \\
\hline 10 & Beaufort, NC, USA & Fixed-wing drone & eBee & $\begin{array}{l}\text { Detectability of shark } \\
\text { analogues }\end{array}$ & Benavides et al. [12] \\
\hline 11 & $\begin{array}{c}\text { Cape Cod, MA, } \\
\text { USA }\end{array}$ & $\begin{array}{l}\text { Underwater drone } \\
\text { (AUV) }\end{array}$ & REMUS-100 & Shark movements & Packard et al. [13] \\
\hline
\end{tabular}


Table 1. Cont.

\begin{tabular}{|c|c|c|c|c|c|}
\hline ID & Location & Drone & Model & Focus & Reference \\
\hline 12 & $\begin{array}{c}\text { Faial Island, } \\
\text { Azores, Portugal }\end{array}$ & Fixed-wing drone & Skywalker X8 & $\begin{array}{l}\text { Detectability of } \\
\text { aggregations }\end{array}$ & Fortuna et al. [14] \\
\hline 13 & $\begin{array}{l}\text { Sea of the } \\
\text { Hebrides, UK }\end{array}$ & $\begin{array}{l}\text { Underwater drone } \\
\text { (AUV) }\end{array}$ & REMUS-100 & Sub-surface behaviour & Hawkes et al. [15] \\
\hline 14 & $\begin{array}{c}\text { Sea of the } \\
\text { Hebrides, UK }\end{array}$ & Multirotor & DJI Phantom 3 Pro & Social behaviour & Gore et al. [16] \\
\hline 15 & $\begin{array}{c}\text { Mossel Bay, South } \\
\text { Africa }\end{array}$ & Multirotor & DJI Phantom 3 and 4 & $\begin{array}{c}\text { Whale hunting } \\
\text { behaviour }\end{array}$ & $\begin{array}{c}\text { Dines and Gennari } \\
{[17]}\end{array}$ \\
\hline 16 & $\begin{array}{c}\text { D'Arros and St } \\
\text { Joseph, Seychelles }\end{array}$ & Multirotor & DJI Phantom 4 & $\begin{array}{c}\text { Whale } \\
\text { scavenging/hunting } \\
\text { behaviour }\end{array}$ & Lea et al. [18] \\
\hline 17 & $\begin{array}{c}\text { Shoalwater, WA, } \\
\text { Australia }\end{array}$ & Multirotor & DJI Mavic Pro & Shoaling behaviour & López et al. [19] \\
\hline 18 & $\begin{array}{l}\text { Kimberly, WA, } \\
\text { Australia }\end{array}$ & Multirotor & DJI Phantom 4 & $\begin{array}{c}\text { Whale } \\
\text { scavenging/hunting } \\
\text { behaviour }\end{array}$ & Gallagher et al. [20] \\
\hline 19 & $\begin{array}{l}\text { Heron Island, } \\
\text { Queensland, } \\
\text { Australia }\end{array}$ & Multirotor & DJI Phantom 3 Pro & $\begin{array}{l}\text { Shark movement } \\
\text { tracking }\end{array}$ & Raoult et al. [21] \\
\hline 20 & $\begin{array}{l}\text { NSW Coast, } \\
\text { Australia }\end{array}$ & Multirotor & DJI Phantom 4 & $\begin{array}{c}\text { Whale } \\
\text { scavenging/hunting } \\
\text { behaviour }\end{array}$ & Tucker et al. [22] \\
\hline 21 & $\begin{array}{l}\text { NSW Coast, } \\
\text { Australia }\end{array}$ & Multirotor & DJI Phantom 4 & Swimming behaviour & Colefax et al. [23] \\
\hline 22 & $\begin{array}{l}\text { NSW Coast, } \\
\text { Australia }\end{array}$ & Multirotor & DJI Phantom 4 & Swimming behaviour & Tucker et al. [24] \\
\hline 23 & $\begin{array}{l}\text { NSW Coast, } \\
\text { Australia }\end{array}$ & Multirotor & DJI Phantom 4 & Detection probability & Colefax et al. [25] \\
\hline 24 & $\begin{array}{l}\text { NSW Coast, } \\
\text { Australia }\end{array}$ & Multirotor & DJI Phantom 4 & Detection probability & Colefax et al. [26] \\
\hline 25 & $\begin{array}{l}\text { NSW Coast, } \\
\text { Australia }\end{array}$ & Multirotor & DJI Matrice & Detection probability & Colefax et al. [27] \\
\hline 26 & $\begin{array}{l}\text { NSW Coast, } \\
\text { Australia }\end{array}$ & Multirotor & DJI Phantom 4 & Faunal richness & Kelaher et al. [28] \\
\hline 27 & $\begin{array}{l}\text { NSW Coast, } \\
\text { Australia }\end{array}$ & Multirotor & DJI Phantom 4 & $\begin{array}{c}\text { Helicopter v drone for } \\
\text { shark detection }\end{array}$ & Kelaher et al. [29] \\
\hline 28 & $\begin{array}{l}\text { NSW Coast, } \\
\text { Australia }\end{array}$ & $\begin{array}{c}\text { Artificial } \\
\text { intelligence }\end{array}$ & Not-specified & Detection probability & Saqib et al. [30] \\
\hline 29 & $\begin{array}{l}\text { NSW Coast, } \\
\text { Australia }\end{array}$ & $\begin{array}{c}\text { Artificial } \\
\text { intelligence }\end{array}$ & Not-specified & Detection probability & Sharma et al. [31] \\
\hline 30 & $\begin{array}{l}\text { NSW Coast, } \\
\text { Australia }\end{array}$ & $\begin{array}{c}\text { Artificial } \\
\text { intelligence }\end{array}$ & Blimp-based system & Shark surveillance & Gorkin III et al. [32] \\
\hline 31 & $\begin{array}{l}\text { NSW Coast, } \\
\text { Australia }\end{array}$ & Multirotor & DJI Inspire 1 & Beach safety & Butcher et al. [33] \\
\hline 32 & $\begin{array}{l}\text { Flinders Island, } \\
\text { Tasmania, } \\
\text { Australia }\end{array}$ & $\begin{array}{l}\text { Underwater drone } \\
\qquad(\mathrm{ROV})\end{array}$ & BlueROV 2 & Post-release behaviour & Raoult et al. [34] \\
\hline
\end{tabular}


Using drones as a shark research tool is a natural extension of aerial monitoring from planes and helicopters, which has been performed for decades. Besides certain known ecosystems (i.e., aggregation sites), it is often difficult to see sharks in the wild and gather data, particularly in the vast expanse of the ocean. Drones offer on-demand, localised piloting and aerial visualization as an effective way to locate, track and study sharks [33]. Recent studies have recommended that drones have the potential to outperform traditional aerial surveys [2]. Furthermore, a huge limitation of studying sharks up close is that some species are potentially dangerous, and drones provide the perfect platform with a controlled aerial viewpoint to enable researchers to study them safely.

With generally declining populations and increasing anthropogenic threats to sharks, there is a critical need to fill knowledge gaps as they are often a cornerstone of various ecosystems $[35,36]$. Additionally, rare but unfortunate shark interactions from certain species can have devastating consequences to animals and humans [37]. There is a recognized need to better understand shark behaviour to preserve the ocean ecosystems, while mitigating negative human-shark interactions.

This review provides a comprehensive analysis of how drones have expanded shark research. In Section 2, we present the usage of drones in context (i.e., a typical deployment). Section 3 then takes an in-depth look at how drones have been used for shark research in the key areas of shark behaviour of predation, social interactions and bite mitigation, as well as critical environments where sharks reside and species-specific studies. We further detail in Section 4 how new technology in sensors, automation, and artificial intelligence, as well as the use of underwater drones, have been developed to increase data quality and enhance our understanding of sharks. Finally, in Section 5, we provide insights into the future of drone development for shark research.

\section{Drones for Studying Sharks}

A standard drone operation consists of an unmanned aircraft, ground control station, and communications link between the two. Typically, the ground control station serves as the communication gateway with a live-feed visualization screen from the camera. For shark research, often the drone will be launched from a beach or vessel serving as the take-off point and operated along a manual or automated flight path over a target area [25]. A pilot who is responsible for controlling the flight operates the drone, and there may be additional personnel who are operating or analysing the camera feed for sharks and at times other relevant wildlife and/or people and infrastructure of interest. Once a shark is spotted, data are collected, mostly in the form of pictures or videos, and recorded either in internal storage on the drone, as part of the ground station, or by recording the feed via a stream at an auxiliary location. Depending on the task, the data can be analysed in real time (for instance to track a specific shark seen on the video feed) and/or videos can be analysed post flight $[25,29]$. There are many parameters to consider when setting up drone-based research for sharks (Figure 2). These can be separated into two main categories: the requirements for surveying and data collection, and the conditions at the study site.

The requirements of the study will dictate the appropriate equipment setup and corresponding analysis techniques. Primarily, the critical requirements for the survey area and the flight time (duration of visualization) will significantly influence the drone type. Fixed-wing and multirotor are two main types of small drones currently suitable for aerial surveys, although hybrids also exist that attempt to combine advantages from both platforms. Fixed-wing drones are typically used for speed and energy efficiency. They can survey comparatively longer distances over $100 \mathrm{~s}$ of kilometres and have flight durations from 20 min to several hours; however, they generally require assistance with taking off ('throwing' by hand or catapult) and a clear area for landing [2]. Multirotor drones are a comparatively new technology and have advantages of rapid vertical take-off and landing capabilities on coastal beaches and vessels. They can also hover and are more dynamic and responsive in movement positioning, however, are more aerodynamically unstable and 
have shorter flight durations of typically 12 to $40 \mathrm{~min}$ [2]. Increasing the energy density of the batteries, using alternative fuel systems, or dual or tethered power systems will provide greater flight times and allow for longer periods of flight, but may add complexity and cost to the drone platform.

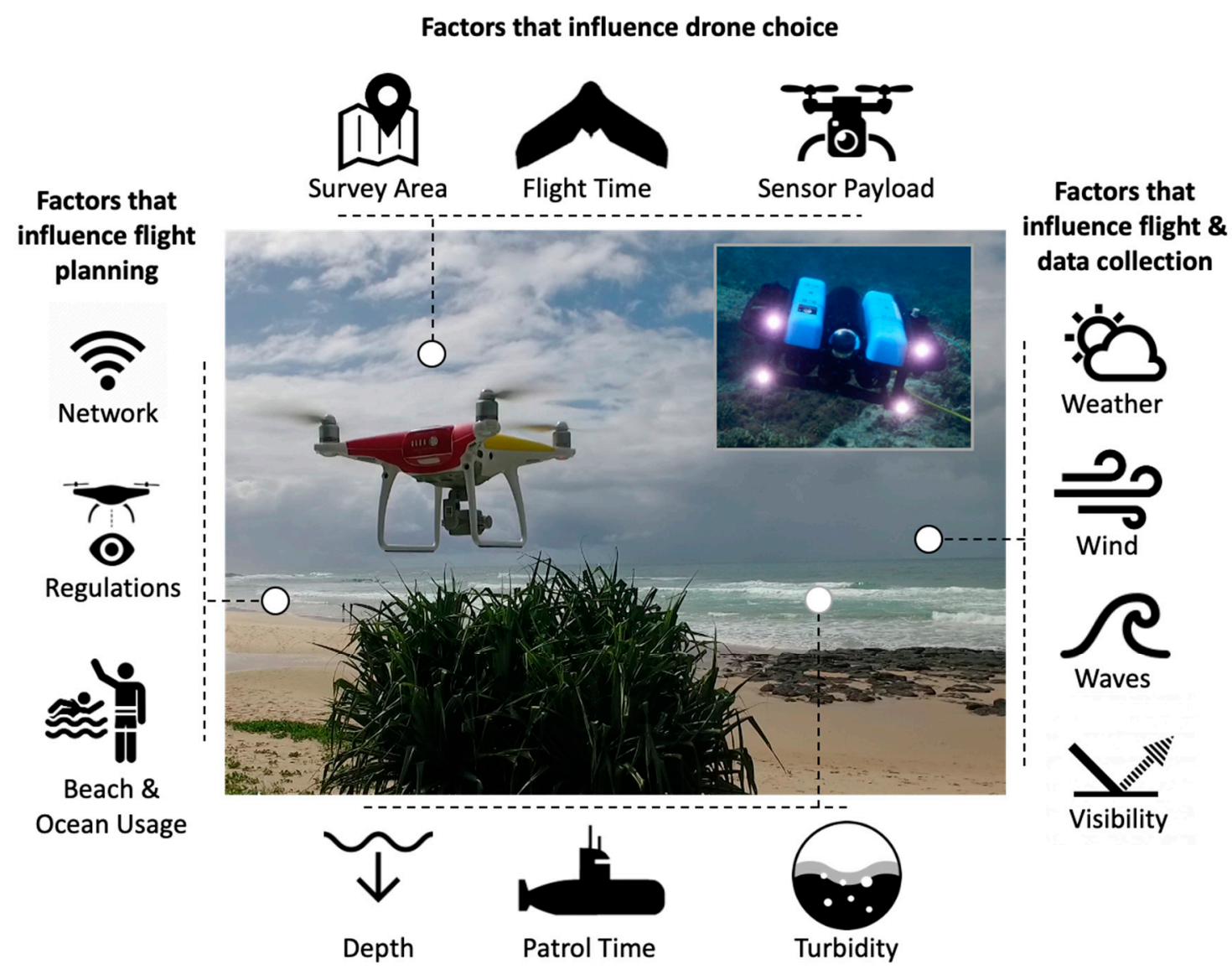

Figure 2. Schematic illustrating the interrelated factors that researchers should consider when planning and performing shark research with drones. (Top) factors that influence the type of drone and payload required for a research activity, (Left) factors that influence pre-flight planning for a research monitoring activity, (Right) factors on the day that heavily influence successful flight and data collection during a research activity. (Inset) image of underwater ROV/UAV and (Bottom) additional factors for underwater drones.

The type of data to be collected will influence the variant of sensor, the type of payload to be attached to the drone, and ultimately the choice of drone for use. Image and video collection are the primary techniques for most shark research and the related equipment is a common feature of the typical drone toolkit. Significant variations on the range of camera types and features for basic visualization are available, and more recently, thermal imaging, LIDAR, and hyperspectral cameras have shown potential for research but are yet to be fully tested. Regardless of imaging equipment, sensor type and drone choice are also influenced by the "data link" requirements of the research. This includes considering the timing of data analysis needed, i.e., can the images/videos be processed after collection, or does analysis need to be in real-time or some step in between. Critically for main studies which require analysis during the flight, the type and transmission of data collection is a fundamental consideration, i.e., the resolution of video telemetry, data bandwidth and meta-data captured. The interrelated requirements of automated flight and data collection are additional worthwhile considerations, if required by the researcher. Additionally, the payload selection directly impacts the weight allowances and capabilities for the drone. Furthermore, drones of increasing weights are divided into different classes. In regard 
to regulation, this can impact the licenses required to fly which must also be considered when preparing for drone research. The interplay of these factors can significantly affect the ultimate drone choice.

The conditions of the study site are highly influential on a shark research experimental plan, impacting both pre-flight planning, and the flight and data collection on the day. Firstly, there are specific conditions that will influence the ability to fly and collect data. This includes the telecommunication availability, particularly any lack of network coverage that can impact flight control and safety, as well as limit visualization of data collection from drones (transmitted video feeds). Furthermore, it is critical to have safe access to the study site (for shark observations this can range from a populated urban beach to an isolated marine reserve). The site-specific conditions can influence how researchers should approach drone use. For instance, operators often are required to avoid flying over people when using drones at recreational beaches. As well, certain locations have additional drone restrictions/prohibitions to reduce wildlife impact. In protected areas like certain parks and sanctuaries, exemptions to no-fly zones are needed, and conditions like altitude limits are imposed to protect marine life and to minimize bird disturbance. These factors are impacted by the technological capabilities of the drone, the "local" aviation laws, the service providers, etc., all of which are critical for planning.

In addition to the general infrastructure and usage at the site, drone-based shark studies are highly dependent on the weather and sea conditions. This goes well beyond above water conditions like wind and rain that limit the ability of drones to fly. Wave conditions are also required to be minimal to avoid distortion on the surface of the water and thus provide a sufficiently clear view of the underwater environment. It is well known that while aerial viewing has significant benefits, the underwater environment imposes constraints to visualization from drones. Primarily the time of day, angle of the sun and resulting reflection, also influence optimal visualization [25,33].

The combination of these factors showcases the difficulties in studying sharks, especially when the most basic principle requires them to be barely sub-surface to be visible. This can occur anywhere in the ocean but most often in shallow water that constrains the animals near the surface. In addition, inhabiting waters must be sufficiently clear to enable the animals to be seen from the air. Some coastal or estuarine habitats are often too turbid (murky, sandy or muddy, etc.) to see anything below the surface. Any of the above constraints will limit the utility of drones for observing shark behaviour. Recent advances in fluid lensing have demonstrated the ability to compensate for surface distortion from drone video and this is a promising area for future development that could provide a clearer view of the underwater environment at small scales [38].

One final consideration is that civil aviation regulations often require training, certifications, and impose specific usage (recreational versus commercial use) and other flight restrictions depending on the jurisdiction. Generally, these rules are evolving and are varied from country to country. One major consideration is that regardless of drone type, size and payload configuration, generally authorities limit flight distances to 'visual lineof-sight', which restricts operations to localized spatial scales (i.e., individual beaches). Beyond line-of-sight operations are currently possible in some areas and countries, however, operations are typically expensive and arguably no longer cost-effective compared with manned aircraft [39]. Therefore, although regulations are likely to be more flexible in the near future, drones have the greatest potential on smaller spatial scales. For safety and effective research execution, the authors strongly advise that any shark researchers interested in using drones seek expert advice and training to gain understanding of local issues and regulations.

The authors would also highlight that most of the factors discussed are similarly important for underwater drones (ROV/UAV) with a few notable additions. For drone choice, a similar discussion to the aerial flight area and time can be made for underwater drones in patrol time and depth required for observations. ROVs are currently directly operated vehicles, meaning they are better at reacting to changing conditions, whereas 
AUVs generally rely on following cues (usually requiring acoustic tags) and using remote acoustic instructions that may not be as flexible as those of an ROV. In unplanned or unknown conditions, the ROV offers more flexibility, even if the deployment capabilities of ROVs are often inferior, especially for range and speed. Both those factors can affect drone choice, particularly in the usage considerations between a submersible drone controlled and tethered from a ship versus autonomous submarine type drone systems. In terms of planning, obviously more consideration must be taken for activity/usage in the water. For conditions on the day, turbidity or the clarity of the environment, water depth, tide and current will absolutely influence the ability to collect images/video/data from underwater based perspectives.

\section{Drone Research Areas}

The following sections provide illustrations of the limited specific research activities that have been conducted so far on sharks using drones, highlighting the breadth of potential of this technology for its application in shark research.

\subsection{Drones as a Tool for Shark Hazard Reduction}

A fundamental issue with the implementation of new methods or 'tools' for shark bite mitigation is the challenge of reliably assessing the direct reduction in shark bite risk due to the rarity of incidents. Between 2015 and 2020, research trials were completed in New South Wales, Australia to assess the utility of drones to provide adequate beach safety with regards to shark bites and provide insight as to whether drones may play a role in future shark mitigation strategies.

In terms of mitigation, drones are an extension of well-established methods for shark identification through aerial monitoring which has occurred for decades [2]. It is widely accepted that specific shark species are more dangerous to humans than others and represent the majority of injuries and deaths recorded (particularly white, tiger, bull sharks) (https: / / www.floridamuseum.ufl.edu/shark-attacks / factors/species-implicated/). Drones can be used to locate and identify sharks, and combined with alerting responsible beach personnel and removing swimmers from the water and/or closing the beach, thereby reduces the risk of attacks through isolating and eliminating the hazard.

Drones have utility for shark surveillance, but are limited in both conditions that make flying difficult, as well as those conditions that affect the ability to detect fauna from aerial positions. From a piloting perspective, most drones can only fly effectively in winds typically up to $\sim 15-18$ knots, and during rain-free periods [25,33] as well as if visibility is not impaired by fog or low altitude cloud cover. Regarding visibility from the air, the reliability of detecting fauna declines as sea conditions and water clarity worsens, just like manned aircraft surveillance [40]. Sighting rates from drones are largely comparable to that of helicopters [29], which can have low detection reliability when conditions are not favourable. These factors complicate shark surveillance, while increasing wind velocities and sea states usually negatively correlate with water users, there is a large degree of variation among beaches, and often there are some water users (e.g., surfers) in circumstances where the reliability of fauna detections may be significantly compromised [25].

Environmental predictors influence the probability of observing the presence of target sharks such as bull (Carcharhinus leucas), tiger (Galeocerdo cuvier) and white sharks (Carcharodon carcharias) [25]. However, water visibility, wind speed and direction seem to have little influence on the behaviour of white sharks while near the surf break. Along the east coast of Australia, swim behaviour of white sharks near the surf break was demonstrated to be largely predictable for this species, as it was shown to be consistently slow at $\sim 3 \mathrm{~km} \mathrm{~h}^{-1}$ and parallel to the beach line [23] (Figure 3a). The slow and predictable track trajectories of white sharks compliments surveillance strategies that can make frequent surveillance passes (Figure 3b). However, although white shark behaviour was consistent across the various study locations, it has been demonstrated to significantly differ near abundant food sources, such as in proximity to seal colonies or when whale carcasses wash 
near shore [24]. Such species-specific information on behaviour can enhance our success of identifying and tracking sharks under different environmental conditions.

(a)

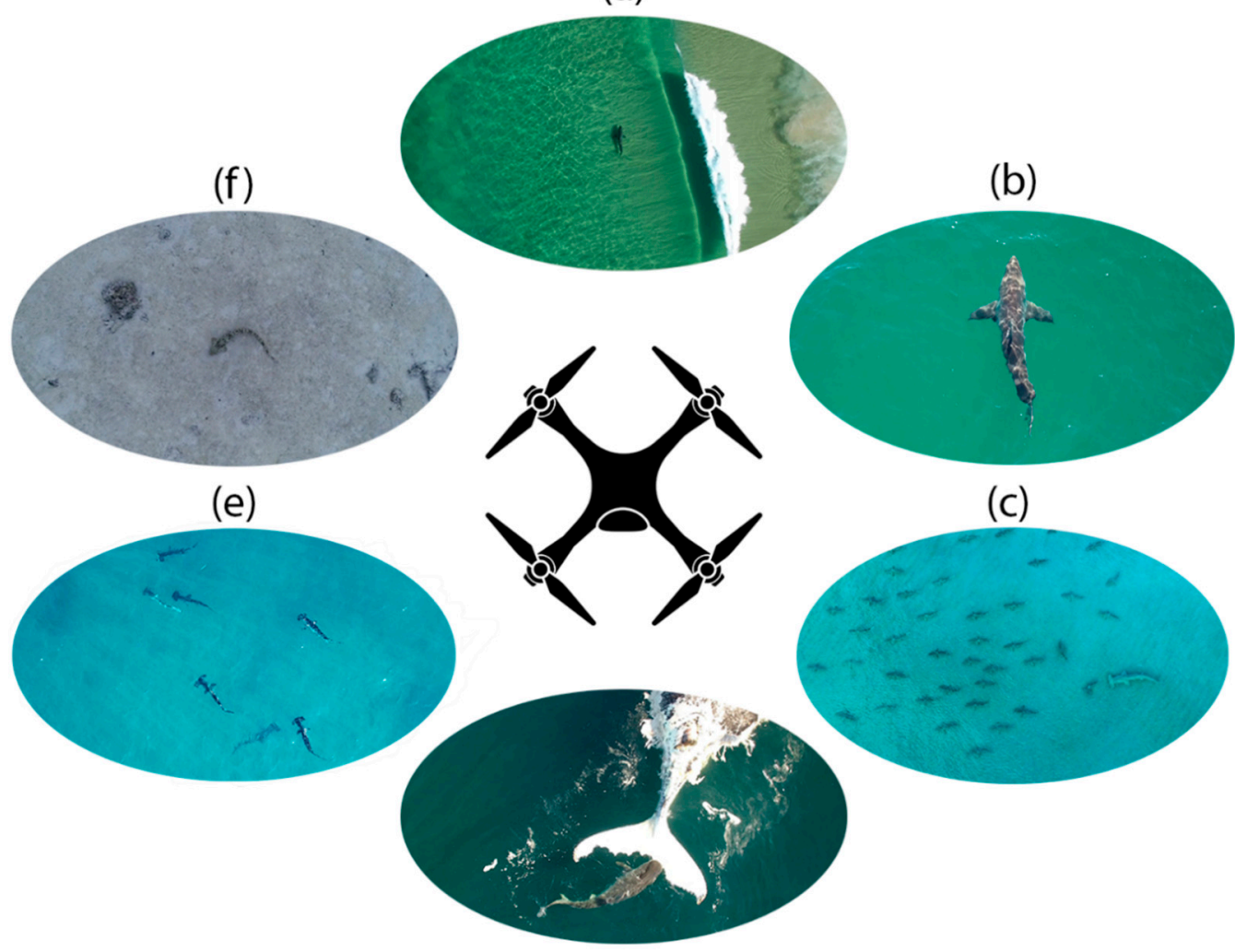

(d)

Figure 3. Representation of the types of imagery collected by drone: (a,b) tracking white sharks (Carcharodon carcharias) along coastal beaches of eastern Australia as part of behavioural and bather protection programs (Image credit-A Colefax), (c) great hammerhead (Sphyrna mokarran) predation event on blacktip sharks (Carcharhinus limbatus) (Image credit-S Kajiura), (d) tiger shark at a humpback whale (Megaptera novaeangliae) carcass off eastern Australia (Image credit-M Dujmovic), (e) hammerhead sharks (Sphyrna sp.) observed during the austral summer in Western Australia (Image credit-N.A. López), and (f) Epaulette shark (Hermiscyllium ocellatum, $\sim 50 \mathrm{~cm} \mathrm{TL}$ ) captured feeding in sediments at low tide on Heron Reef flat, Great Barrier Reef, Australia from an altitude of $5 \mathrm{~m}$ (Image credit-V. Raoult).

Currently, drones are one socially preferred method for assisting shark bite mitigation through hazard reduction, along with other monitoring techniques, particularly compared with cull-based strategies [41]. This is despite a sentiment of concern around the reliability of detection during unfavourable weather conditions, and the ability to effectively discriminate between shark species by the pilots. It demonstrates that further development of drones as a shark bite mitigation tool is warranted, particularly in the areas of improving detection reliability and efficiency of individual species identification. Such improvements in utility should further increase the positive community sentiment and further reduce shark bite risk potential.

While the reliability of drone-based shark surveillance can likely be further improved with spectral filtering and recognition software ([30,32], see Section 4.1 and Section 4.2), the largest improvements to efficiency will occur with system automation. However, as coastal air spaces often also have high air traffic activity, it is unlikely that civil aviation authorities would approve beyond line-of-sight flights there. However, in coming years this will likely change. Therefore, advancing and integrating detection software in drone-based shark surveillance will have short-term benefits regarding detection reliability, but also facilitate automation in the longer-term. Even with those advances, the authors would 
caution against an overreliance on detection technologies including drones. It is unlikely that drones will replace spotting from trained professionals (lifeguards and lifesavers) for the foreseeable future.

Drones have strong potential for providing adequate risk reduction in the potential for shark bites, appease public needs and perceptions of beach safety, and support conservation. Therefore, drones can play a pivotal role in transitioning away from shark bite mitigation using cull-based strategies and help meet the increasing demand for non-destructive beach safety [26]. In addition, drone-based surveillance can potentially provide opportunistically collected data to conservation agencies as a by-product [28,42,43]. With further research and development, the utility of drone-based surveillance will further increase, as should public perceptions, particularly if operations remain incident-free [41].

\subsection{Drone Studies of Shark Predation Events}

Natural predation is notoriously difficult to document in the wild. Predation events occur infrequently, and the events are often brief. Therefore, the probability of being in the right place at the right time to witness a natural predation event is low and it is easier to see the results after the fact. For example, scientists have used the presence of a large blood slick on the surface of the water to determine that a white shark had predated upon a pinniped, despite not seeing the actual predation event itself [44]. In addition, the presence of the observer can alert prey or impact the behaviour of the predator, potentially resulting in an aborted predation attempt. These complications are amplified when dealing with underwater animals. In the underwater realm, all the same constraints apply with some additional difficulties. The time available to wait and observe a predation event underwater is limited by scuba or rebreather capabilities, with available duration inversely proportional to increasing depth. Underwater visibility is greatly limited compared to in air. This requires the observer to be much closer to the animals which can, in turn, impact their natural behaviour. However, under some circumstances it is possible to bypass some of these constraints to remotely observe natural predation.

Drones provide an opportunity to unobtrusively observe underwater animals, if they are sufficiently near to the surface. At altitudes greater than 5-10 m, the sound produced by most small drones is undetectable above background levels underwater [45]. A small drone flying overhead would also be nearly impossible to distinguish from underwater. Thus, unless the drone is close to the water's surface where it could be detected by the animals, the behaviours documented are likely to be natural and not impacted by the observer. Another advantage of using drones to record natural predation events is the stability that they confer. Unmanned aerial vehicles can hover in place using GPS positioning. Coupled with gimbal-stabilized cameras, this provides a highly stable video recording platform that facilitates quantification of predator and prey movement with respect to each other. This enables observations to incorporate quantitative data, such as distance between individuals, or swimming velocity in body lengths per second, rather than being merely descriptive [46].

An ideal location that satisfies the requirements to visualize shark predation using drones is the southeast coast of Florida, USA. The nearshore environment is characterized by a uniform, light sandy seafloor that allows the dark shape of sharks to be clearly seen. In addition, the continental shelf narrows in southeast Florida, which allows the Gulf Stream current to transport clear water close to shore providing good visibility. Each winter, thousands of blacktip sharks (Carcharhinus limbatus) aggregate in the shallow water along the coast where they are observed from the air [47]. These sharks are prey to larger sharks, such as the great hammerhead (Sphyrna mokarran) (Figure 3c) [48]. Drones have been used to document great hammerhead sharks attempting to prey upon blacktips in the shallows [11]. These natural predation events reveal hammerhead sharks cruising slowly in the nearshore environment with numerous blacktips nearby. The hammerhead will suddenly accelerate rapidly and chase down a blacktip. The featureless sandy seafloor provides no structure or shelter and the blacktips often flee to the shallow water adjacent to the beach. The much larger hammerhead shark is unable to follow into the shallows and turns back to deeper 
water, allowing the blacktips to escape. Documentation of the use of shallow water as a refuge was only possible because of the aerial view provided by the drone. Although other studies have examined social behaviour of sharks with drones $[4,8,16,18]$, Doan and Kajiura's [11] study is the first to document predator avoidance behaviour by large adult sharks. The regular predictable occurrence of large numbers of sharks in a nearshore environment with clear water provides a rare opportunity to use drones to observe and study natural predation in the wild.

\subsection{Drone Studies of Shark Behaviour and Social Interactions}

Drones have recently been used to record and study collective shark behaviour. Drone footage can be analysed in depth to quantify swimming alignment, nearest-neighbour distances, velocity (based on static fly and landmarks) and tail beat frequency (Figure 4). For example, Rieucau et al. [4] used an image analysis-based technique applied to drones and showed that blacktip reef sharks (Carcharhinus melanopterus) displayed increased alignment with shoal companions when distributed over a sandflat where they are regularly fed for ecotourism purposes as compared with when they shoaled in a deeper adjacent channel. Using similar methods, it could be possible to study the collective response of shoaling sharks to predation risk using drone-based methods [11] for example, by measuring the transfer of information between individuals following the approach of the predator. Drones can also be used to reveal the fine-scale interaction rules of mass migrating elasmobranchs $[16,47,49]$, as has been done for other terrestrial mammal species [50].
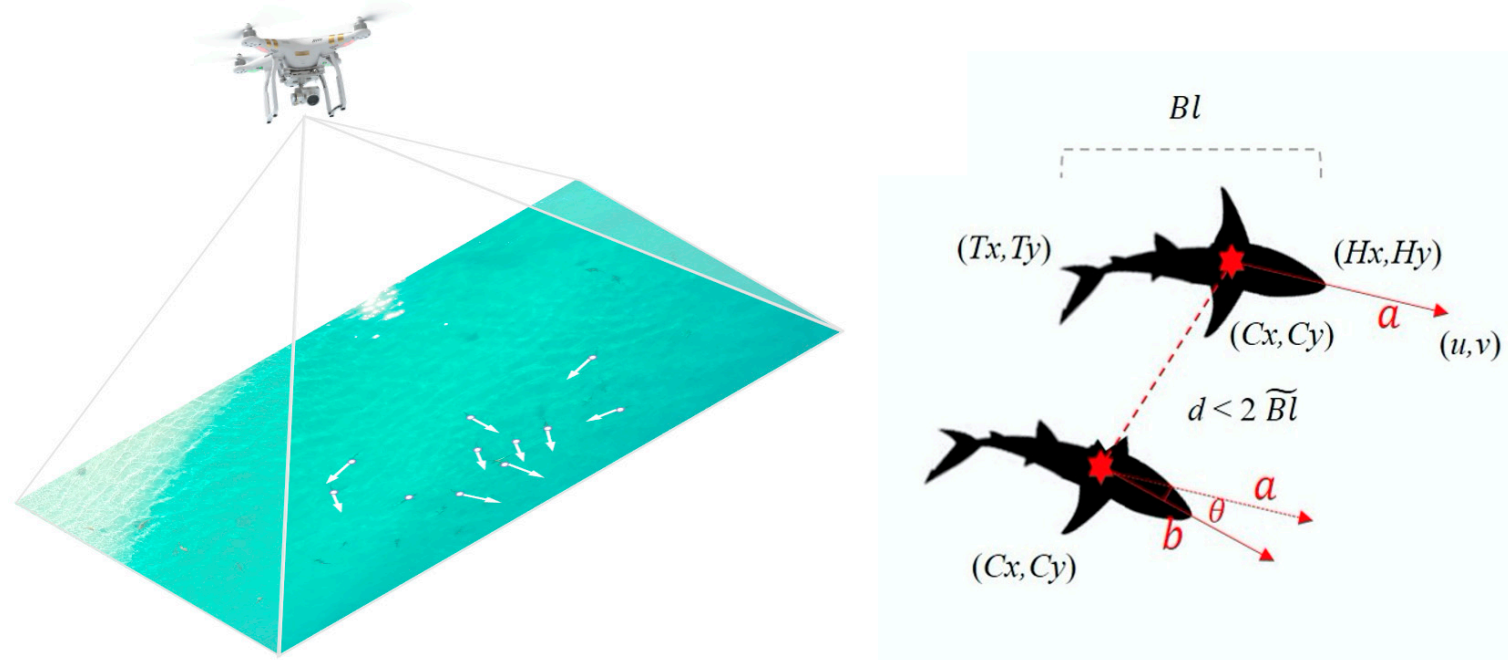

Figure 4. Drone footage can be analysed to quantify swimming alignment, nearest-neighbour distances, velocity and tail beat frequency (Image-modified by J Mourier from Rieucau et al., 2018).

Quantifying social interactions and building social networks may be limited using drones because it requires identifying individuals within observed groups over multiple sampling periods to infer the association indices calculated from the repeatability of interactions-not currently an easy task with drones. However, drones can be used to record group size in elasmobranchs [49] or to document social behaviour and frequencies of such behaviours [16]. For example, Gore et al. [16] used a combination of boat surveys, snorkelling and drones to record the frequency of close-following, parallel or echelon swimming and breaching of basking sharks (Cetorhinus maximus). Post-processing techniques can also be used to determine the track and path of multiple individual sharks within a frame [21], which can be used to measure interactions and encounters between multiple individuals. Although such analysis may be limited due to the short sampling increments of the drone, some social measurements can still be recorded such as the frequency of associating with another shark versus swimming alone. 
Drones are still constrained by many practicalities that would limit the study of collective behaviour and social interactions in elasmobranchs. The first one is that aerial drone surveys are limited to record behaviour at the surface in shallow environments. While some shark and ray species can display collective and social behaviour at the surface that can be easily captured by drones, most species spend considerable time at relatively greater depths beyond the vision of the drones. Moreover, drone operations can be significantly impacted by environmental conditions as flights require good weather conditions and optimal sunlight, and are restricted to daylight surveys [51]. Another current important issue is the short battery life and flight duration. While battery technology and subsequent capacity delivery for a given weight continuously improves, current multirotor flights rarely last more than 20-30 min, which can affect the robustness of sampling social interactions.

\subsection{Shark Behaviour around Whale Carcasses}

Natural shark behaviours are often difficult to observe due to their habitats and relatively low abundance. Larger shark species, such as bull, tiger and white sharks, are often transitory in nature making it more difficult for researchers to observe natural behaviours [52]. Feeding events are situations where the natural behaviour of low-density organisms can be observed. Many species of shark feed on whale carcasses and research suggests that sharks can locate these carcasses over great distances [53]. This makes whale carcasses excellent opportunities for observing shark behaviour (Figure 3d).

Drones can be used to observe sharks hunting and scavenging from whales in their natural habitat with minimal disturbance to individuals [17,20,22] (Figure 3d). Bull, tiger, tawny nurse (Nebrius ferrugineus), and white sharks have been observed scavenging whale carcasses using drones [22]. Small and cost-effective drones have the resolution to capture shark behaviours and interactions at whale carcass scavenging events from heights that do not influence natural behaviour $(\sim 30 \mathrm{~m})$. Behaviours observed include test biting, head shaking, palatoquadrate protrusion, ocular rotation, nictitating membrane use and intra and interspecific interactions [22]. The behaviour of white sharks hunting a live whale has been recorded including approach direction, approach angle, head shaking, and bite location and frequency [17].

Drones are an excellent tool for observing shark behaviour in these events as the top-down view and high resolution allows researchers to observe from a height that includes all sides of a whale simultaneously and the area directly adjacent. Therefore, behaviours such as approach angle/direction and intra and interspecific interactions can be observed. Sharks feeding underneath a whale can also be observed (depending on water clarity) which has not been possible in the past without the use of a shark cage that may influence behaviour. This gives researchers an additional view of an event and behaviours displayed, including some subtle communication behaviours sharks are known for [54]. Researchers are also able to pilot a drone from a distance that does not influence shark behaviour unlike traditional, handheld cameras which require an operator be close to a carcass. Dicken [55] recounts white sharks biting the propellers and pontoons of their boat while filming a scavenging event with traditional cameras, suggesting that these methods do affect behaviour and that drones can be considered a more effective tool for collecting data without altering shark behaviour.

Stranded whale carcass management is a controversial topic due to perceived shark attraction [56,57] and initial results suggest that shark behaviour is altered by the presence of a stranded carcass [24]. Behaviours can be compared to that of sharks not near stranded carcasses [23] to better understand shark behaviour around certain stimuli. Shark speed, total length, and track straightness and sinuosity can be effectively recorded using drones by remaining directly over a shark while matching its movement speed and heading with the camera set in nadir [23]. Results from these studies are relevant to beach management as significant food sources may alter the behaviour of large sharks and increase risk to water users. Drones have been shown to be effective tools for bather protection in normal 
conditions [33] and can be utilised in a similar manner, around whale carcass standing events, to reduce risk of shark interactions with water users.

Operating drones around cetaceans and sharks can be more complex than operating around sharks alone. Some countries have cetacean exclusion zones for drones. In Australia, for example drones are prohibited to come within $100 \mathrm{~m}$ of live whales and dolphins in New South Wales and within $300 \mathrm{~m}$ in South Australia. While some cost-effective drones have the zoom and/or resolution to collect detailed observations from $100 \mathrm{~m}$ altitude, $300 \mathrm{~m}$ would require specialty cameras, and therefore larger, more expensive and more complex drones, to collect data in the resolution required to effectively analyse. While this is not an issue around cetacean carcasses, observing interactions between sharks and live cetaceans, including potential predation, may be difficult in some countries. This, coupled with the rarity of witnessing such an event, may limit the observational data drones can collect. Advances in drone and camera technologies will likely increase their usefulness in these situations as cameras with higher resolution and better zoom are becoming increasingly smaller, lighter and more cost effective, thereby allowing for their inclusion on smaller drones.

\subsection{Drone Research of Pelagic Shark Aggregations}

Pelagic sharks are amongst the most threatened of vertebrates globally, with at least three-quarters of all species assessed as Threatened or Near Threatened by the IUCN [35,58]. They are considered extremely valuable in commercial and recreational fisheries [59-61] and, consequently, this group has been heavily exploited during the last decades decimating their populations across all oceans $[36,62,63]$. Their conservative life-history traits, including longevity, late sexual maturity and few offspring, renders pelagic sharks highly vulnerable to anthropogenic threats $[64,65]$.

A number of pelagic sharks show aggregation behaviour close to the surface or in shallow coastal areas during different life stages. These aggregations can represent feeding or breeding locations when adults $[16,66]$, and nurseries or growing grounds during early life stages [67-69]. Their aggregation behaviour also increases their vulnerability to exploitation [70,71], hence monitoring their distribution and behaviour during these periods is vital for appropriate management and conservation [70,72-74]. For example, knowing where and when they aggregate can inform spatial protection management strategies, such as marine protected areas and fisheries management. Technological advances in new non-invasive and cost-efficient methods such as drones provide researchers with the opportunity to study the fine-scale movements and behaviour of pelagic shark species in shallow coastal environments, complementing the use of traditional methods.

Hammerhead sharks (Sphyrnidae) are an excellent candidate for drone studies and provide a clear example of the potential of drones to study other pelagic shark species that aggregate in shallow coastal waters. Their laterally elongated head shape, or cephalofoil, makes them unmistakable from other sharks in the Carcharhiniformes [75]. The great, scalloped and smooth hammerheads are considered large species within the group [76] that translates into easier aerial detection. These species have global distributions and are known to travel hundreds to thousands of kilometres $[77,78]$ between shallow coastal habitats $[79,80]$. Their behaviour differs noticeably: while great hammerheads tend to inhabit coastal waters and are solitary [76], scalloped and smooth hammerheads occur in the open ocean and are known to form large aggregations near oceanic islands and seamounts when adults [70,81] and coastal aggregations while in neonate and juvenile stages [82-84].

The first aerial study of the spatial ecology of hammerhead sharks (Sphyrna spp.) using manned aircraft dates from the 1980s [85]. This study quantified seasonal patterns in the abundance of hammerheads in relation to sea surface temperature and the Gulf Stream in Florida, USA. Since then, records of hammerheads have been reported in multiple marine megafauna aerial studies [86-88] but have yet to be the focus of drone-based studies in terms of ecology or behaviour. To date, three studies explored hammerhead detectability from manned and unmanned aerial vehicles [12,14,40]. In 2014, Robbins et al. [40] studied shark detectability from fixed-wing and helicopter aircrafts using shark analogues with 
different shapes including, white, tiger and hammerhead sharks (Sphyrna spp.). Although they observed overall low detectability rates, the only mock "sharks" successfully identified by the spotters where those with the hammerhead shape. Two further studies have evaluated hammerhead shark detectability using fixed-wing drones: Fortuna et al. [14] tested the detectability of juvenile hammerhead aggregations (Sphyrna spp.) off the coast of Faial Island, Azores, demonstrating the potential of drones for identifying hammerhead aggregations. More recently, Benavides et al. [12] demonstrated the effect of environmental variables on the detection probability of mock bonnethead sharks (Sphyrna tiburo), a small coastal species, in a temperate estuarine area, concluding that depth had the strongest effect on detectability rates. As of writing, there was only one study that documented hammerhead shark behaviour using drones [11]. The authors documented predatory avoidance behaviour of great hammerhead sharks and blacktip sharks in shallow coastal waters off Florida, USA, demonstrating that drones can be successful in elucidating the behaviour of hammerhead sharks [11]. In addition, drones have been used to study the southernmost aggregation of hammerhead sharks (Sphyrna sp.) in Western Australia, following reports of a consistent seasonal but unstudied aggregation [López, unpublished work; Figure 3e].

The potential of drones as a non-invasive and cost-effective method to study hammerhead sharks in shallow coastal areas is clear, prompting future work and should be extended to other endangered sharks that school. Application of demonstrated methodologies using drones to study shark shoaling behaviour [4], movement trajectories, and habitat use $[3,21,23]$ will be extremely beneficial to better understand how these endangered species are using coastal areas to inform better spatial management and conservation strategies.

\subsection{Drone Studies of Reef Sharks}

Shallow water sharks found in coral reefs are the focus of scientific research for most elasmobranchs [89]. Among species of reef shark, there is a dearth of research on many smaller or cryptic genera in this category [90]. Low numbers of studies may be driven by the difficulty accessing the shallow reefs where many reef-associated species such as epaulette sharks (Hermiscyllium ocellatum) occur (Figure 3f). Shallow reefs are often complex habitats that are generally only accessible by foot at low tide or by boat at high tide: this makes using common abundance or behaviour survey techniques difficult to use effectively. Most studies to date examining the movement and behaviour of reef sharks in shallow lagoons rely on acoustic tagging [91,92], but these have limits in lagoon environments due to unreliable detection distances [93]. Baited remote underwater video systems (BRUVS) that are often used to assess reef shark abundance and diversity rely on bait to attract species of interest [94], meaning that they are not able to assess natural behaviour and habitat use. Researchers can use RUVS to remove the effect of bait on behaviour, but they are limited in their visibility and probability of observation making them less efficient for determining abundance and assessing behaviours of sharks. When being in the water is possible, snorkelers or divers also impact natural shark behaviour $[95,96]$ making the separation of natural from human-induced behaviours difficult. Drones are less limited by tides in shallow reef environments and can circumvent some of these issues by providing a platform to assess abundance, diversity, movement and behaviour of these animals with low impact and at relatively low cost. In addition, the barrier reefs that often surround these environments limit wave clutter that can make drone research more difficult [97]. In shallow reef environments, drones can obtain information that would otherwise require tagging or visual censuses. For example, by using the drone onboard GPS it is possible to assess links between movement and habitat use and behaviour of sharks at very high $(<1 \mathrm{~m})$ spatial resolutions, albeit over relatively shorter timeframes $(<20 \mathrm{~min})$ than with tagging approaches with current drone battery technology [21]. One way to extend these tracks is to use at least two drones to relay flights as batteries run out as in Colefax, et al. [23], but eventually pilot fatigue is likely to reduce the accuracy of this approach similarly to typical $\sim 6 \mathrm{~h}$ limits used in active acoustic tracking [98]. The only limits to numbers of active tracks 
of sharks using drones are the number of available batteries, pilot fatigue and weather, meaning that in ideal conditions with a battery recharge station and multiple pilots/drones it is possible to obtain large datasets rapidly. Since the drone-based tracks are shorter than active surface tracking, which can last for 24+ h [99], obtaining datasets that are sufficiently large to infer habitat use and behaviour from drones thus require more individual tracks than tagging approaches. However, the trade-off from using drones is obtaining higher resolution data than tagging approaches, and the ability to directly examine behaviours.

Drones can also be used to assess the abundance and diversity of sharks and rays in reef habitats. For example, by conducting line transects with drones, Kiszka, et al. [3] were able to identify difference in densities of sharks and rays in various reef locations. Drones were also effective at counting and identifying reef sharks and rays in impacted and pristine lagoons [10]. In shallow reef environments, it should be possible to obtain morphometric data on reef sharks and rays in a similar process as those used on whales [45] since shallow depths are unlikely to affect measurements. The use of drones may thus provide an alternative rapid approach for assessments of shark populations in shallow reefs, especially compared to more conventional methods like BRUVS or capture and release programs that impact behaviour and may come at a cost to the health of the animal. To date, most dronebased shark population assessments have relied on multi-rotors that have comparatively limited flight times relative to fixed-wing drones [2], and, for these applications fixed-wing drones may be preferable for larger survey areas similar to conventional aircraft [100].

The quantitative movement or behaviour of sharks in these environments is a useful metric, but haphazard flights can also reveal novel behaviours and inter-specific interactions that open new avenues of research. For example, drone flights along shallow beaches revealed that blacktip sharks use these shallow environments to seek refuge from great hammerhead sharks known to predate on them [47]. Flights over a reef lagoon at low tide revealed active foraging of blacktip reef sharks (C. melanopterus) and epaulette sharks feeding on prey in bare sediment [21] (Figure 3f). Use of drones allows the safe observation of large numbers of reef sharks including tiger sharks scavenging whale carcasses [18]. A greater availability and willingness to use drones during reef shark research projects should allow new insights into their behaviour and ecology.

In these shallow reef environments, drones currently provide one of the only means to study shark behaviour, distribution and abundance. The use of drones in these environments, however, is relatively novel and there are few long-term studies that have relied on this approach to obtain conservation-relevant data. Satellite and acoustic tagging programs initially encountered similar difficulties as sample sizes were low, yet global datasets are now available that have allowed inferences to be drawn at scales never before possible. As drones become more commonly used tools for shark research in shallow reefs, larger drone-based datasets will allow broader examinations of ecological patterns of shark movement, habitat use, and behaviour not obtainable with other approaches. For example, since drone movement data are georeferenced at high resolutions, large drone-based datasets could examine questions around the use of landmarks or 'highways' in shallow reefs to move across reef lagoons, and whether movement of sharks in these areas has effects on other species of shark and fishes that can be visible concurrently. The use of drones in these environments could therefore be used to start making explicit links between behaviour, movement and habitat, which has not been achievable using any single method before drones. The power of drones to map shallow reefs and also provide bathymetric data at very high resolutions (e.g., $\sim 1 \mathrm{~cm}$ positioning error, [101-103] should facilitate this objective.

\section{Enabling Technologies for Future Drone-Based Shark Research}

\subsection{Alternative Sensors on Drones for Shark Research}

Cameras are rapidly increasing in functionality, obtaining higher resolutions and progressively more compact and lightweight. For drone platforms, gimbal systems and telemetry systems have also improved to allow advanced camera stabilisation and highdefinition transmission of video in real time. This has effectively increased the utility of 
drones and subsequent use in ecology in recent years [2,104,105]. Similarly, the advances in electronic component miniaturisation have allowed alternative sensors, such as thermal infrared, multispectral (such as red edge and near infrared) and hyperspectral systems to be mounted on small drones of less than $25 \mathrm{~kg}$, and some micro-sensors on drones that are less than $2 \mathrm{~kg}$ [106]. Such alternative sensors are available in different spatial resolutions, just like their RGB counterparts. However, the spectral accuracy and resolution is also a major consideration and usually scales with cost. Alternative sensors are typically used when spectral information is desired that is also outside of the visible spectrum [105], or when measurements of specific wavelengths are desired, such as for differentiating objects or condition from spectral signatures [107,108].

The advantage of using drone-mounted platforms [109] as opposed to manned aircraft or satellite is in the added flexibility of data acquisition timing, cost considerations, or increased spatial resolution that comes with being nearer the ground $[97,110]$. This also applies to the use of alternative sensors, especially considering the lower spatial resolutions that are often associated. The vast majority of drone-based research on marine fauna is currently done with RGB sensors. This is largely due to (1) the low signal to noise ratio that occurs because of the attenuation properties of water, and the lack of transmission of ultraviolet, near infrared and infrared wavelengths [107,111]; and (2) the additional cost and expertise associated with integration, operation and data interpretation when using alternative sensors. Consequently, the scope for which alternative sensors may offer to marine fauna research, including observing sharks, has not yet been thoroughly researched.

Not surprisingly, most use cases of thermal infrared and multispectral sensors on fauna have been in terrestrial environments. The use of thermal has enabled increased detection rates compared with RGB when there is sufficient temperature difference between target individuals and their surroundings $[112,113]$. Thermal infrared has also been used in the marine environment; however, utility is restricted to animals breaking the surface [114]. In these cases, focus has been on detection at night or investigating temperature differentials as indicators of animal health, such as in the case of whales [114,115]. However, because of the submerged nature of sharks, using thermal infrared wavelengths for detection or remotely investigating thermal properties of sharks will have little utility.

Alternatively, multispectral sensors have been reported as proof-of-concept to improve on the detection rates of marine fauna offered from human spotters or RGB cameras $[116,117]$. However, to our knowledge, no independent empirical assessments on the potential increase in detection reliability have been made. Drone-mountable multispectral cameras usually have a five or six band array, covering the colour range to red-edge or near-infrared, and currently with full width at half maximum bandwidths typically between 10 and $40 \mathrm{~nm}$, depending on the model. Fretwell, et al. [118] used imagery, comprising 8 colour bands (one red-edge) and a panchromatic band, from the WorldView2 satellite, to detect whales in Golfo Nuevo Bay, Argentina. They found that of the available bands, the coastal band (wavelengths $400-450 \mathrm{~nm}$ ) provided the best sub-surface features of whales due to the better water penetration. Similarly, multispectral sensors may have utility in providing enhanced detection of sharks from the air over RGB cameras, by selecting one or two of the narrow colour bands. However, the ideal wavelengths and bandwidths likely differ between locations, conditions and time of day.

Hyperspectral sensors have been used in shallow coral environments to create habitat maps, differentiate between coral types and to assess coral health through empirically assessing reflectance signatures $[109,110]$. Due to the light attenuation properties of water, these studies typically use submersible hyperspectral units. From the air, the signal to noise ratio decreases, however, airborne (drone-based) hyperspectral systems have proven useful for detecting degrees of coral bleaching [119]. It is likely that submersible hyperspectral sensors might have some utility on underwater drones for depicting features of demersal elasmobranchs. Whether different features or species of elasmobranch have measurably separable spectral signature remains uncertain. From the air, differentiating sharks from other fauna based on spectral signatures might be difficult as the signal to noise ratio 
decreases with the animal's depth due to light attenuation. However, there is likely utility in using hyperspectral sensors to define or isolate wavelengths that provide optimal sightability of sharks [2]. This approach is similar to that discussed with multispectral sensors, however, due to the comparatively numerous wavelength channels on a hyperspectral sensor, the identification of ideal wavelengths to increase detectability of sharks is likely to be much more precise.

\subsection{Artificial Intelligence for Shark Monitoring, Detection, and Alerting}

Artificial intelligence (AI), encompassing systems using machine learning (ML), deep learning and computer vision, is revolutionising ecology research across aquatic and land environments. Particularly in recent years, the development of standardised algorithms and the wide availability of automated sensing platforms have led to a paradigm change in survey capability. It is now possible for AI systems to automate aspects of flight and the detection and measurement of target species in all kinds of sensor data (e.g., photographs, video, sound recordings and spectra). Such automated systems will make collection of science-ready data significantly easier and cheaper, facilitate far-reaching citizen science programs and assisting beach managers in reliably identifying potentially dangerous shark species in real-time.

Ecologists focusing on terrestrial environments have been at the forefront of this new wave. They have paired drone platforms and AI techniques to catch poachers [120,121], count animals [122-124], detect invasive weeds [125], map forests [126,127] and monitor plastic pollution [128] - amongst many other uses. By comparison, the adoption of AI techniques in the marine context has been slower, likely because dynamic aquatic environments are more difficult to operate in and present greater challenges to the algorithms (see Dujon and Schofield [129] for a recent review).

One of the earliest automated aerial surveys for marine fauna is by Maire et al. [130], who used a convolutional neural network $(\mathrm{CNN})$ to detect dugongs in aerial survey images. By modern standards the network architecture was very simple, containing only three convolutional blocks, which likely contributed to the high number of false positives they report. Despite this, such deep learning techniques are now recognised as being state-ofthe-art for computer vision tasks. Modern CNNs are at the heart of mission-critical systems like self-driving cars, e.g., [131,132] and healthcare diagnostic tools, e.g., [133].

CNN-based systems have been enthusiastically developed for the aquaculture industry, where they have been deployed to identify fish species and measure their physical properties-tasks directly relevant to shark research. Although usually applied to imagery from underwater cameras, the underlying algorithms and training workflows are also directly applicable to aerial imagery. For example, AI applied to underwater videos has been very successfully demonstrated by Ditria et al. [134]. The authors used object detection algorithms to track and identify fish species seen in video feeds from underwater cameras at fixed locations. They demonstrated that the methods could be made to work well on previously unseen data and on novel data from completely different sites. A key innovation here was the development of an integrated active-learning software platform called FishID (https: / globalwetlandsproject.org/tools/fishid/) that allows new data to be rapidly tagged and assimilated into an improved model. In another example, Fernandes et al. [135] tackled a related challenge to segment the anatomy of fish species in order to estimate body volume. This was largely accurate when applied in a controlled setting (fish out of water on a uniformly lit background) but performance degraded when the system was applied to other species, or in situ.

These exemplar studies and similar research showcase the possibilities of AI in a marine setting. However, applying AI techniques to aerial imagery of ocean scenes is generally more difficult because the dynamic air-water interface distorts sub-surface shapes. In addition, the fidelity and quality of images are affected by weather conditions, water turbidity and the presence of confusing objects (e.g., submerged reef, rocks and seaweed, and floating foam). 
The use of AI has shown immediate value to assist researchers with shark detection, species identification and real-time alerting to beach users. There are several AI-based shark detection systems in development globally and most of these focus on applying computer vision techniques to aerial imagery. One striking exception is the work by Hughes and Burghardt [136] who identify individual white sharks from imagery of their dorsal fins (Figure 5). Their system applies computer-vision segmentation techniques to extract candidate fin boundaries, which are then refined using a random forest ML algorithm. The unique biometric notch patterns at the trailing edges of each fin are encoded and matched to known individuals using a Bayesian nearest-neighbour classifier. The authors report an average precision of $81 \%$ and expect the system to work well with other species of shark. Another notable example is Clever Buoy, developed in a commercial collaboration between Shark Mitigation Systems Ltd. and Tritech International Ltd. This system deploys sonar transducers to detect moving objects in the water and uses AI to identify sharks over two meters in length via their distinctive movement patterns.

\section{Evolution of Al for Shark Identification}

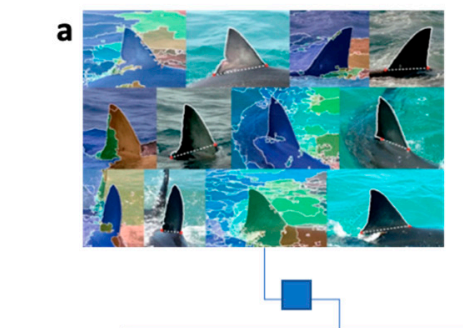

c

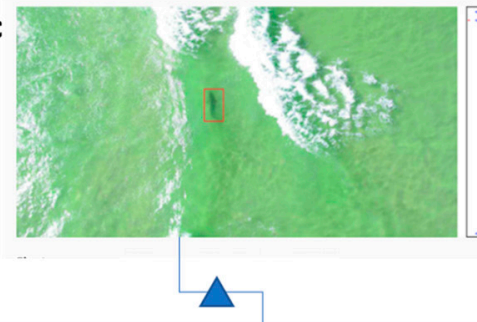

Al analysis of images

Al analysis of captured drone video feeds

Al analysis of live drone video feeds

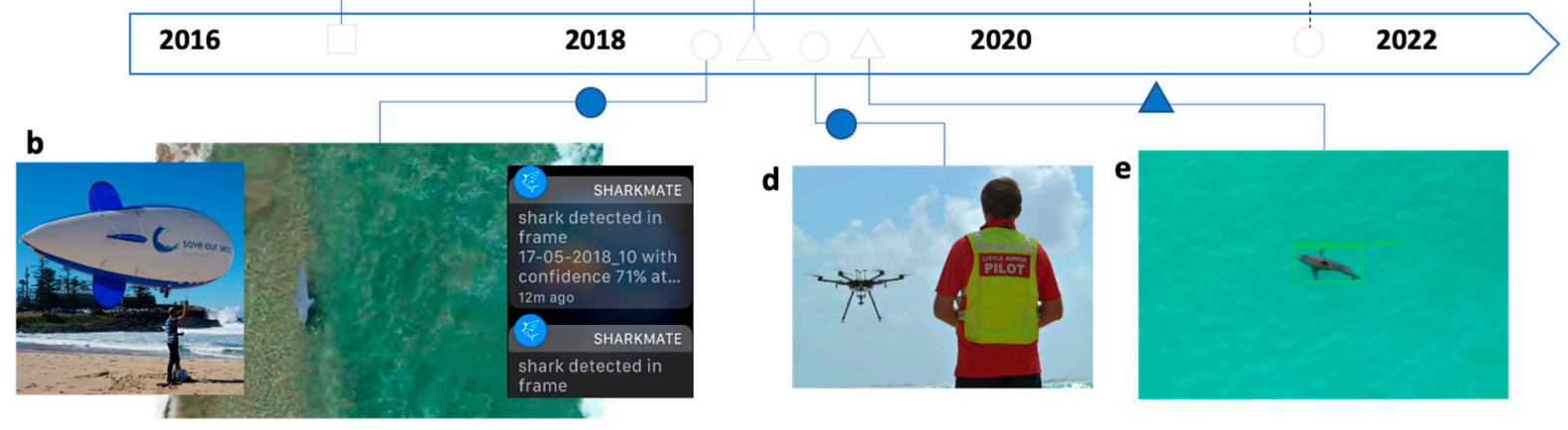

Figure 5. Evolution of artificial intelligence (AI) for shark identification: (a) automated evaluation of dorsal fins from video collected developed by Hughes and Burghardt [136], (b) real time evaluation of shark analogues at beach (with reporting to in-water users) demonstrated in Kiama, Australia through blimp and drone-based camera feeds by Gorkin et al. [32] (University of Wollongong, May 2018), (c) automated marine animal detection based on images collected over Australian beaches post-collection (Sharma et al. [31]) (UTS Nov 2018), (d) UTS system was reportedly deployed on Little Ripper Drones in NSW beaches in Australia with Surf Life Saving as of 2019, (e) Sharkeye system reported by San Diego State University and Sales Force-where videos collected from drones flown over Southern California could be analyzed and reported to lifeguards (2019), and (f) in development AI on portable devices that can identify to species level in real time by Macquarie University and NSW Department of Primary Industries research teams.

The majority of systems under development have focused on building AI systems that learn salient features from a library of drone footage and apply this learned model to detect sharks in live video streams. Candidate detections are annotated on visualisation devices deployed in the field, either performing inference on-device or at a remote server. The Little Ripper Group deployed one of the first such drone-based AI shark detection systems in Australia (Figure 5). Developed in partnership with the University of Technology Sydney, the shark-spotting system operated on a live video feed from drones flown above 
NSW beaches. Sharma et al. [31] reported on the initial development of the CNN-based models used to detect and localise sharks, and other marine objects. In their non-fieldbased tests the VGG16 network architecture delivered the most robust detections of sharks (mAP $>90 \%$ ) when applied to a 30\% testing set drawn from the ensemble data. Although accurate, VGG16 is a resource-intensive network and required desktop-class computing hardware to achieve high frame rates (Sharma et al. [31] report a NVIDIA Quadro P6000 GPU delivered an inference time of $0.130 \mathrm{~s}$ ).

Other organisations have further expanded on these initial results, although these have not yet been published as peer-reviewed papers. In the USA a team from UC Santa Barbara's Benioff Ocean Initiative, in collaboration with Salesforce AI Research and computer scientists at San Diego State University, have developed a system they call SharkEye. According to their web page (https: / / www.sharkeye.org), data collection is done via RGB cameras on drones flown over the beaches. The live video stream is processed on remote servers, feeding a system that broadcasts real-time alerts to beach users.

In Australia, researchers from the University of Wollongong have developed a similar end-to-end platform that operates with any aerial imagery (they present a case study on a beach, based on blimp- and drone-mounted cameras). Also called SharkEye, the system described in Gorkin et al. [32] performs inference in the cloud and delivers push notifications to Apple mobile devices both on land, and critically, in the water, as the first demonstration of personalized alerting to swimmers and surfers in real-time. Gorkin et al. [32] report accuracies of $91.7 \%, 94.5 \%$ and $86.3 \%$ for sharks, stingrays, and surfers, respectively. However, these metrics were derived from a limited sample of images and the authors acknowledge that the purpose was to demonstrate the flexibility of the technology platform, and like other groups with limited data collection, their specific detection models will likely not generalise well to other locations, or environmental conditions. Finally, several other small organisations have launched demonstrators of shark-detection systems. For example, Greenroom Robotics (https:/ / greenroomrobotics.com) built a proof-of-concept drone-based system for a company on Reunion Island.

The greatest challenge for drone-based AI shark detection is the issue of generalisation. Current systems are limited by: (1) the narrow range of environmental conditions sampled in the training data, (2) the small and skewed distributions of species observed, (3) low overall numbers of training images and (4) the small number of field sites sampled that are not broadly representative. A generally useful shark detector would need to address all these issues.

Supervised learning AI systems are trained using an iterative process that requires accelerated computing hardware to progress in a reasonable time (typically 1-2 days). High-quality annotated datasets are the key to building high-performing models and these are extremely time-intensive to create. The data must reflect the full range of conditions encountered in the field and (at least initially) human experts are required to manually label each object of interest. However, the labelling process can also be assisted by AI tools-once reasonable object detection models are available.

We note that the studies reported above assess performance by testing on a small sub-sample split from their training data. Such tests can be misleading for the reasons given above and reported accuracies are unlikely to hold when deployed in the field. The tests essentially answer the question 'How well does the AI know the current data?' rather than 'How well does the AI solve the problem?'. In particular, the visual appearance of beaches in different locations can vary dramatically, meaning that even a well-trained algorithm would need tuning to avoid significant false positive detections. This problem is known as 'domain shift' and can be mitigated by using an active learning system that facilitates the rapid assimilation of new data into the AI model.

Tools for active learning have started appearing in the literature recently. These take the form of software that predict labels for new data and allow an 'oracle' user to make corrections via an interactive graphical interface (e.g., ICON by Gonda et al. [137], RootPainter by Smith et al. [138], FishID by Ditria et al. [134] and the Transfer Sampling 
method by Kellenberger et al. [139]). A large trial (involving some of the authors of this manuscript) of AI shark detection algorithms on drones has recently been completed in NSW, Australia to systematically test the ability of ML algorithms to distinguish between shark species, and to determine how well algorithms can generalise across a range of water and environmental conditions. Over $4 \mathrm{~TB}$ of data was gathered at five beaches on the NSW coast during March-June 2020, covering a wide range of environmental conditions. The scientific team developed in-house active learning tools to assist with labelling the dataset and expect to release results of the trial in early 2021. The goal is to deploy a robust and accurate software tool to assist beach managers in confidently identifying potentially dangerous sharks in real time. Further enhancements will aim to mitigate against surface distortions, e.g., [140] and apply photogrammetric methods, e.g., [141] to measure shark size, orientation and swim-parameters [8].

Taken as a whole, these capabilities have the potential to transform any intelligent device into a data-gathering tool. For example, such automated systems could be the foundation of a high-quality citizen science program. Members of the public could report shark sightings using their personal drones, reporting consistent measurements and uncertainties. Ecological surveys that once required expensive helicopters and manual labour could be achieved with few resources and to greater reliability. Once properly calibrated, automated measurements could correct for confounding environmental conditions and supply trustworthy quality-control flags and other essential metadata. Finally, drone systems are already being deployed for spotting potentially dangerous sharks at public beaches. If AI systems live up to their promise, then automated shark detection and tracking from drones could be an unremarkable and trusted presence at public beaches in the near future.

\subsection{The Potential of Underwater Drones}

Over the past decade, underwater drones that use similar control software and hardware as aerial drones have been developed to actively track marine animals while collecting direct behavioural observations and environmental data [142-146]. There are two main types of underwater drones: autonomous underwater vehicles (AUVs) and remotely operated vehicles (ROVs) (Figure 6). Autonomous underwater vehicles track an acoustically tagged shark with or without any direct input from the pilot and without a link to the surface, are typically torpedo-shaped, and as a result have 3 axes of movement (pitch, yaw, roll) and only forward and reverse propulsion. Remotely operated vehicles (ROVs) for the most part require manual operation and are tethered to the surface but can manoeuvre with 6 degrees of freedom in any direction or orientation. Autonomous underwater vehicles have been used more often to study sharks, so we focus primarily on these machines here.

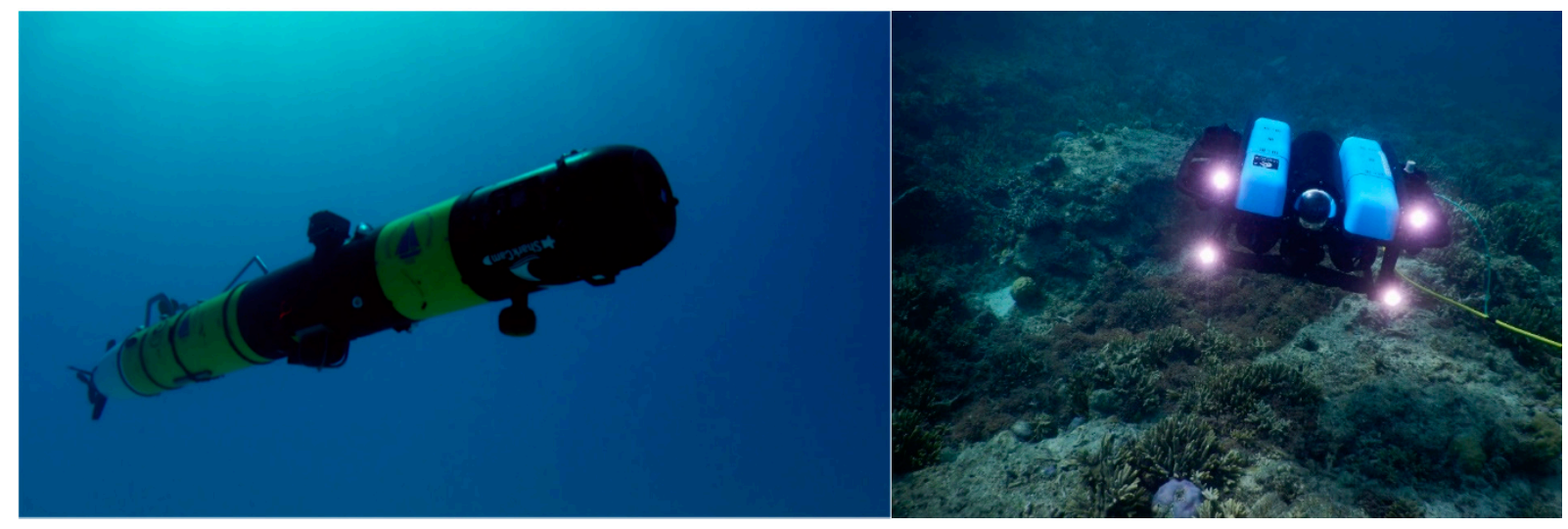

Figure 6. Examples of 'underwater drones' used for shark research. REMUS Automated Underwater Vehicle (AUV) used to track acoustically-tagged white sharks (Carcharodon carcharias) (left: Image—G Skomal), and BlueRobotics BlueROV2, a tethered, manually controlled remotely operated vehicle used to track untagged sharks post release (right: Image- T Gaston). 
The first attempts to autonomously track a fish with an underwater drone involved the use of a $3 \mathrm{~m}$ kayak equipped with a hydrophone, receiver, and GPS that could follow a simulated acoustically tagged fish from the surface for up to $24 \mathrm{~h}$ [144]. Subsequent studies used a self-propelled, subsurface AUV to passively collect data on acoustically tagged Atlantic sturgeon (Acipenser oxyrinchus), winter flounder (Pseudopleuronectes americanus), shortnose sturgeon (Acipenser brevirostrus), summer flounder (Paralichthys dentatus), and sablefish (Anoplopoma fimbria) by canvassing an area along a pre-programmed path $[145,146]$.

The first to use an underwater drone to study sharks was Clark et al. [9], who actively tracked an acoustically tagged leopard shark (Triakis semifasciata) in a coastal lagoon. In that study, the drone was constrained to the surface, was not equipped with cameras (for behavioural observations), lacked the capacity to monitor animal depth, and resulted in a coarse estimate of the shark's horizontal movements. Packard et al. [13] were the first to mount cameras on an underwater drone for the sole purpose of observing behaviour while actively tracking sharks and collecting environmental data at depth. These authors used a REMUS (Remote Environmental Monitoring UnitS; Woods Hole Oceanographic Institution, Woods Hole, MA, USA) drone, which was developed as a platform for a wide variety of oceanographic instrumentation and outfitted with a Global Positioning System (GPS), wireless communication, iridium capabilities, an inertial navigation system, ring laser gyroscopes to orient the vehicle spatially, and accelerometers to sense changes in speed and velocity [9]. The drone also carried a variety of sensors including an acoustic Doppler current profiler, a conductivity-temperature probe, magnetic heading sensor, and pressure sensor. During this study, basking and white sharks were tracked at depth off the coast of Cape Cod, MA and direct observations (video) and environmental data were collected, thereby demonstrating that an AUV could actively and accurately track large (>2 m) sharks in shallow waters $(<20 \mathrm{~m})$ [13].

With improvements to tracking capabilities, Skomal et al. [6] used this same drone technology to investigate the behaviour, habitat use, and feeding ecology of white sharks off Guadalupe Island, Mexico. In that study, six drone missions were conducted on four white sharks, ranging in estimated total length from 3.9-5.7 m, for durations of 1.4-2.9 h. Based on over $13 \mathrm{~h}$ of behavioural data, this study showed that the white sharks remained in the area for the duration of each mission and moved through broad depth and temperature ranges from the surface to $163.8 \mathrm{~m}$ and 27.1 to $7.9^{\circ} \mathrm{C}$, respectively [6]. Video footage and drone sensor data revealed that two of the white sharks being tracked and eight other white sharks in the area approached, bumped, and/or bit the AUV during these tracks [6]. Not only did this study demonstrate that a drone could be used to effectively track and observe the behaviour of a large shark, but it also produced the first observations of subsurface predatory behaviour for this species.

Using the behavioural and environmental datasets generated by these tracks and three additional missions, Gabriel [7] conducted more detailed analyses related to underwater drone performance, white shark behaviour, and environmental correlates. This study concluded that the drone was not only able to track sharks more accurately, both horizontally and vertically in the water column, than traditional vessel-based methods, but also provided fine-scale, environmental datasets related to the tracks and direct observations of white shark behaviour [7]. Using data collected by the drone, the first estimates of swimming speed and course relative to water current direction/strength and changes in depth were calculated for this species [7]. In addition, the influence of environmental factors (e.g., temperature, time of day, tides, depth of thermocline, bathymetry, and water current magnitude and direction) on swimming behaviour were also investigated [7]. Video observations collected by the on-board cameras allowed for the calculation of tailbeat frequency, which remained consistent across tracks and swimming speeds [7]. Using a manually piloted and tethered underwater drone controllable with 6 degrees of freedom (remotely-operated vehicle (ROV), BlueRobotics BlueROV2) [147] obtained similar metrics from small sharks (Cephaloscyllium laticeps, Squalus megalops) released into the ocean, albeit over shorter durations than possible with AUVs. 
Based on these studies, underwater drones can be used to monitor, follow, approach, and image a randomly moving shark. These vehicles, which can be readily deployed in waters inaccessible to, or unsafe, for divers (e.g., remote, rough seas, where sharks are feeding), can produce high precision tracks $[6,147]$ while collecting environmental data and behavioural imagery over periods of several hours. Moreover, these vehicles are versatile and highly customizable, and can take on different payloads to meet scientific goals (e.g., underwater sonar, CTD probes, Niskin bottles). There is also evidence that underwater drones may be less obtrusive than other commonplace sampling or active tracking approaches [148] and may be superior for surveying abundance or behaviours of sharks and rays than divers or snorkelers. However, like their aerial counterparts, underwater drones might affect the natural behaviour of sharks. For example, the noise from an AUV's propeller might influence behaviour the same as a boat engine during active tracking. It is anticipated that new advances in this field will ultimately be used to collect observations over broader temporal and spatial scales and across many species [15,34], and like aerial drones, the costs of these machines are decreasing rapidly.

\section{Outlook and Conclusions}

Drones have greatly enhanced the scope of research possible for scientists and managers [149]. Sharks are inherently difficult to study due to their often migratory nature, their sub-surface habits and the potential for negative human-shark interactions, particularly in species that are potentially more dangerous to humans. Such data are particularly important for many species where our understanding of their ecological importance in marine ecosystems remains rudimentary. Sharks that inhabit shallow coastal environments often occur in turbid waters or along breaking waves on beaches, making direct observations difficult. Until recently, monitoring and observing the natural behaviour of sharks has been limited to invasive tagging studies, animal-borne video, underwater diver surveys, deployment of remote stationary cameras (baited or unbaited) or aerial surveys. Tagging and animal borne video require capture and there is potential for injury and behavioural changes of the animals. These techniques also typically assess animal movement on larger temporal and spatial scales. Scuba surveys are limited by the constraints of the divers and the potential aggressiveness of the focal species, and remote cameras cannot track individuals and are limited to whatever swims past a small field of view. Manned aerial surveys allow vast distances to be covered quickly and can be effective for individual shark tracking but are expensive, both financially and in labour. This review discusses the roles that drones offer as non-intrusive and effective methods of surveying and tracking sharks, and monitoring their behaviours.

Specific requirements and conditions need to be met to successfully deploy drones for shark research. Once a researcher has established the appropriate equipment and training, drones offer efficient, reliable and cost-effective ways to collect spatially explicit data that have previously been unavailable through other methods. Drones offer direct visualisation of sharks for surveying and mitigation strategies and technology is now underway that allows managers to spot and monitor the behaviour of individuals to assess their risk of interaction with humans in real time. Researchers have had the opportunity to document direct predation events and associated behaviours of sharks in the wild and interactions with each other without disturbance, sometimes for the first time, via drone technology. Such behaviours are inherently difficult to document due to their brief and sporadic nature and drones offer a highly opportunistic method for data collection in such events. Similarly, ecological aspects of threatened species and those in complex habitats that are difficult to monitor effectively via other technologies have been successfully assessed using drones.

The use of drones in shark research and management has rapidly risen in the past five years and is projected for exponential increase, particularly if key technical challenges are overcome. Many of these emerging technologies are already being developed, as discussed in this review. Drone sensors, and camera quality and functionality need to be further optimised to allow for higher definition video to be transmitted in real time and for 
improved detection of sub-surface sharks. Drone design and battery improvements must continue to allow for longer airtime and data collection. Advances in larger multirotor systems such as hexacopters offer possibilities for refining lifting and deployment of heavy equipment for shark-associated activities or interactive sampling and manipulation (i.e., drone imagery for $3 \mathrm{~d}$ reconstruction of the body). Refinements to AI and ML are necessary to optimise and automate processes for detection, identification and tracking sharks from live video feed. This is particularly important considering the current bottleneck of intensive data processing and video analysis and would pave the way for easier comparisons between species in different ecosystems and environments. Finally, improvements in the tracking capabilities, speed, manoeuvrability and broader depth ranges of autonomous underwater vehicles are needed to jettison the capabilities of underwater drone use for shark researchers studying deeper water or benthic species. Unique opportunities also arise to pair aerial and underwater drone studies to allow for an integrated comparison of shark behaviour from above and below.

It should be noted that regardless of the technological advances for drones and their post video processing, ultimately the ubiquity of drone use for shark research comes down to the expertise of the user, issues associated with flying beyond line-of-sight distance, and with navigating a diversity of weather conditions. Increased training, situational awareness and thorough flight protocols can all lessen the potential for error, but it is difficult to imagine a scenario where human error will be eliminated from the process entirely. Drone flights beyond line-of-sight are increasing in popularity as this allows tracking of sharks as they venture further from the operator but also increases risk and decreases safety. Finally, there are some weather conditions that make drone flight too hazardous, regardless of the importance of the research at stake. As weather is inherently changeable, it is prudent to have the ability to adequately forecast weather before and during flight.

Our understanding of shark behaviour has been limited to date by difficulties in obtaining direct observations of rare behaviours and fine-scale, spatially explicit data. The use of drones in observing sharks allows scientists, managers, other stakeholders and the broader community the opportunity to document real-time behavioural events in relative safety. Documenting behaviours via video and imagery has the added advantage of creating an historical record of an event that may form the foundations of future research not considered at the time of data collection. This opportunistic footage taken by a drone enthusiast may be valuable to researchers and managers, aligning interests of researchers with those of the broader community. Such documentation can also be used to increase public understanding of sharks and help challenge the inaccurate dogma of sharks being killing machines that require lethal deterrent measures.

Author Contributions: Conceptualization, P.A.B., V.R. and A.P.C.; methodology, all authors equally; writing - original draft preparation, all authors equally; writing — review and editing, all authors equally; project administration, P.A.B. All authors have read and agreed to the published version of the manuscript.

Funding: This research was funded by multiple sources related to individual authors and their projects. These include (in alphabetical order): ARC LIEF Grant (LE170100007), Australian Government, RTP Scholarship Centre de Recherche Insulaire et Observatoire de l'Environnement (CRIOBE), Colgan Foundation, Department of Biological Science at Macquarie University, Discovery Communications, Jock Clough Marine Foundation (through the Oceans Institute Robson and Robertson Award), NSW Department of Primary Industries (through the Shark Management Strategy), Save our Seas Foundation (Small grant SOSF 283), Sci-eye, Sea World Research and Rescue Foundation (SWR/13/2018), Southern Cross University and Woods Hole Oceanographic Institution.

Institutional Review Board Statement: Not applicable.

Informed Consent Statement: Not applicable.

Acknowledgments: Thank you to the following people for their contributions to the projects encompassed in this review: Kevin Boswell, Craig Brand, Jose Carlos Castillo, Mike Heithaus, Brendan 
Kelaher, Kirk Gastrich, Jeremy Kiszka, Jessica Meeuwig, Guillaume Rieucau, Louise Tosetto and the many pilots and observers that made these shark projects possible.

Conflicts of Interest: The authors declare no conflict of interest.

\section{References}

1. Chapman, A. It's okay to call them drones. J. Unmanned Veh. Syst. 2014, 2, iii-v. [CrossRef]

2. Colefax, A.P.; Butcher, P.A.; Kelaher, B.P. The potential for unmanned aerial vehicles (UAVs) to conduct marine fauna surveys in place of manned aircraft. ICES J. Mar. Sci. 2018, 75, 1-8. [CrossRef]

3. Kiszka, J.J.; Mourier, J.; Gastrich, K.; Heithaus, M.R. Using unmanned aerial vehicles (UAVs) to investigate shark and ray densities in a shallow coral lagoon. Mar. Ecol. Prog. Ser. 2016, 560, 237-242. [CrossRef]

4. Rieucau, G.; Kiszka, J.J.; Castillo, J.C.; Mourier, J.; Boswell, K.M.; Heithaus, M.R. Using unmanned aerial vehicle (UAV) surveys and image analysis in the study of large surface-associated marine species: A case study on reef sharks Carcharhinus melanopterus shoaling behaviour. J. Fish Biol. 2018, 93, 119-127. [CrossRef] [PubMed]

5. Frixione, M.G.; García, M.D.; Gauger, M.F.W. Drone imaging of elasmobranchs: Whale sharks and golden cownose rays co-occurrence in a zooplankton hot-spot in southwestern Sea of Cortez. Food Webs 2020, 24, e00155. [CrossRef]

6. Skomal, G.B.; Hoyos-Padilla, E.M.; Kukulya, A.; Stokey, R. Subsurface observations of white shark Carcharodon carcharias predatory behavior using an autonomous underwater vehicle. J. Fish Biol. 2015, 87, 1293-1312. [CrossRef] [PubMed]

7. Gabriel, S. Using Autonomous Underwater Vehicles to Assess the Habitat Use and Swimming Behavior of White Sharks (Carcharodon carcharias). Master's Thesis, University of Massachusetts, Dartmouth, MA, USA, 2018.

8. Ho, C.; Joly, K.; Nosal, A.P.; Lowe, C.G.; Clark, C.M. Predicting Coordinated Group Movements of Sharks with Limited Observations using AUVs. In Proceedings of the Symposium on Applied Computing, Marrakech, Morocco, 3-7 April 2017; pp. 289-296.

9. Clark, C.M.; Forney, C.; Manii, E.; Shinzaki, D.; Gage, C.; Farris, M.; Lowe, C.G.; Moline, M. Tracking and following a tagged leopard shark with an autonomous underwater vehicle. J. Field Robot. 2013, 30, 309-322. [CrossRef]

10. Hensel, E.; Wenclawski, S.; Layman, C.A. Using a small, consumer-grade drone to identify and count marine megafauna in shallow habitats. Lat. Am. J. Aquat. Res. 2018, 46, 1025-1033. [CrossRef]

11. Doan, M.D.; Kajiura, S.M. Adult blacktip sharks (Carcharhinus limbatus) use shallow water as a refuge from great hammerheads (Sphyrna mokarran). J. Fish Biol. 2020, 96, 1530-1533. [CrossRef]

12. Benavides, M.T.; Fodrie, F.J.; Johnston, D.W. Shark detection probability from aerial drone surveys within a temperate estuary. J. Unmanned Veh. Syst. 2020, 8, 44-56. [CrossRef]

13. Packard, G.E.; Kukulya, A.; Austin, T.; Dennett, M.; Littlefield, R.; Packard, G.; Purcell, M.; Stokey, R. Continuous autonomous tracking and imaging of white sharks and basking sharks using a REMUS-100 AUV. In Proceedings of the 2013 Ocean Sciences Meeting, San Diego, CA, USA, 23-27 September 2013; pp. 1-5.

14. Fortuna, J.; Ferreira, F.; Gomes, R.; Ferreira, S.; Sousa, J. Using low cost open source UAVs for marine wild life monitoring-Field report. IFAC Proc. 2013, 2, 291-295. [CrossRef]

15. Hawkes, L.A.; Exeter, O.; Henderson, S.M.; Kerry, C.; Kukulya, A.; Rudd, J.; Whelan, S.; Yoder, N.; Witt, M.J. Autonomous underwater videography and tracking of basking sharks. Anim. Biotelem. 2020, 8, 29. [CrossRef]

16. Gore, M.; Abels, L.; Wasik, S.; Saddler, L.; Ormond, R. Are close-following and breaching behaviours by basking sharks at aggregation sites related to courtship? J. Mar. Biol. Assoc. UK 2019, 99, 681-693. [CrossRef]

17. Dines, S.; Gennari, E. First observations of white sharks (Carcharodon carcharias) attacking a live humpback whale (Megaptera novaeangliae). Mar. Freshw. Res. 2020, 71, 1205-1210. [CrossRef]

18. Lea, J.S.E.; Daly, R.; Leon, C.; Daly, C.A.K.; Clarke, C.R. Life after death: Behaviour of multiple shark species scavenging a whale carcass. Mar. Freshw. Res. 2019, 70, 302-306. [CrossRef]

19. López, N.A.; McAuley, R.; Meeuwig, J. Identification of the southernmost aggregation of juvenile scalloped hammerhead sharks (Sphyrna lewini) in Australia. 2021; in prepare.

20. Gallagher, A.J.; Papastamatiou, Y.P.; Barnett, A. Apex predatory sharks and crocodiles simultaneously scavenge a whale carcass. J. Ethol. 2018, 36, 205-209. [CrossRef]

21. Raoult, V.; Tosetto, L.; Williamson, J.E. Drone-Based High-Resolution Tracking of Aquatic Vertebrates. Drones $2018,2,37$. [CrossRef]

22. Tucker, J.P.; Vercoe, B.; Santos, I.R.; Dujmovic, M.; Butcher, P.A. Whale carcass scavenging by sharks. Glob. Ecol. Conserv. 2019, 19, e00655. [CrossRef]

23. Colefax, A.P.; Kelaher, B.P.; Pagendam, D.E.; Butcher, P.A. Assessing white shark (Carcharodon carcharias) behaviour along coastal beaches for conservation-focused shark mitigation. Front. Mar. Sci. 2020, 7, 268. [CrossRef]

24. Tucker, J.P.; Colefax, A.P.; Santos, I.R.; Kelaher, B.P.; Pagendam, D.E.; Butcher, P.A. White shark behaviour altered by stranded whale carcasses: Insights from drones and implications for beach management Ocean Coast. Manag. 2021, $200,105477$.

25. Colefax, A.P.; Butcher, P.A.; Pagendam, D.E.; Kelaher, B.P. Reliability of marine faunal detections in drone-based monitoring. Ocean Coast. Manag. 2019, 174, 108-115. [CrossRef]

26. Colefax, A.P.; Butcher, P.A.; Pagendam, D.E.; Kelaher, B.P. Comparisons of localised distributions of white, bull, and tiger sharks using three tech-based methods. Ocean Coast. Manag. 2020, 198, 105366. [CrossRef] 
27. Colefax, A.P.; Kelaher, B.P.; Walsh, A.J.; Purcell, C.R.; Pagendam, D.E.; Cagnazzi, D.D.B.; Butcher, P.A. Utility of spectral band selection from drone-based hyperspectral imagery for improving detectability of submerged marine fauna. Biol. Conserv. 2021, submitted.

28. Kelaher, B.P.; Colefax, A.P.; Tagliafico, A.; Bishop, M.J.; Giles, A.; Butcher, P.A. Assessing variation in assemblages of large marine fauna off ocean beaches using drones. Mar. Freshw. Res. 2019, 71, 68-77. [CrossRef]

29. Kelaher, B.P.; Peddemors, V.M.; Hoade, B.; Colefax, A.P.; Butcher, P.A. Comparison of sampling precision for nearshore marine wildlife using unmanned and manned aerial surveys. J. Unmanned Veh. Syst. 2019, 8, 30-43. [CrossRef]

30. Saqib, M.; Khan, S.D.; Sharma, N.; Scully-Power, P.; Butcher, P.; Colefax, A.; Blumenstein, M. Real-time drone surveillance and population estimation of marine animals from aerial imagery. In Proceedings of the 2018 International Conference on Image and Vision Computing New Zealand, Auckland, New Zealand, 19-21 November 2018; pp. 1-6.

31. Sharma, N.; Scully-Power, P.; Blumenstein, M. Shark Detection from Aerial Imagery Using Region-Based CNN, a Study; Mitrovic, T., Xue, B., Li, X., Eds.; AI 2018: Advances in Artificial Intelligence; Springer International Publishing: Cham, Switzerland, 2018; pp. 224-236.

32. Gorkin, R., III; Adams, K.; Berryman, M.J.; Aubin, S.; Li, W.; Davis, A.R.; Barthelemy, J. Sharkeye: Real-Time Autonomous Personal Shark Alerting via Aerial Surveillance. Drones 2020, 4, 18. [CrossRef]

33. Butcher, P.; Piddock, T.; Colefax, A.; Hoade, B.; Peddemors, V.; Borg, L.; Cullis, B. Beach safety: Can drones provide a platform for sighting sharks? Wildl. Res. 2019, 46, 701-712. [CrossRef]

34. Raoult, V.; Tosetto, L.; Harvey, C.; Nelson, T.M.; Reed, J.; Parikh, A.; Chan, A.J.; Smith, T.M.; Williamson, J.E. Remotely operated vehicles as alternatives to snorkellers for video-based marine research. J. Exp. Mar. Biol. Ecol. 2020, 522, 1-10. [CrossRef]

35. Dulvy, N.K.; Fowler, S.L.; Musick, J.A.; Cavanagh, R.D.; Kyne, P.M.; Harrison, L.R.; Carlson, J.K.; Davidson, L.N.; Fordham, S.V.; Francis, M.P.; et al. Extinction risk and conservation of the world's sharks and rays. eLife 2014, 3, 1-34. [CrossRef]

36. Roff, G.; Brown, C.J.; Priest, M.A.; Mumby, P.J. Decline of coastal apex shark populations over the past half century. Commun. Biol. 2018, 1, 1-11. [CrossRef]

37. Pepin-Neff, C.L.; Wynter, T. Reducing fear to influence policy preferences: An experiment with sharks and beach safety policy options. Mar. Policy 2018, 88, 222-229. [CrossRef]

38. Chirayath, V.; Earle, S.A. Drones that see through waves-Preliminary results from airborne fluid lensing for centimetre-scale aquatic conservation. Aquat. Conserv. Mar. Freshw. Ecosyst. 2016, 26 (Suppl. 2), 237-250. [CrossRef]

39. Ferguson, M.C.; Angliss, R.P.; Kennedy, A.; Lynch, B.; Willoughby, A.; Helker, V.; Brower, A.A.; Clarke, J.T. Performance of manned and unmanned aerial surveys to collect visual data and imagery for estimating arctic cetacean density and associated uncertainty. J. Unmanned Veh. Syst. 2018, 6, 128-154. [CrossRef]

40. Robbins, W.D.; Peddemors, V.M.; Kennelly, S.J.; Ives, M.C. Experimental evaluation of shark detection rates by aerial observers. PLoS ONE 2014, 9, e83456. [CrossRef] [PubMed]

41. Stokes, D.; Apps, K.; Butcher, P.A.; Weiler, B.; Luke, H.; Colefax, A.P. Beach-user perceptions and attitudes towards drone surveillance as a shark mitigation tool. Mar. Policy 2020, 120, 104127. [CrossRef]

42. Provost, E.J.; Butcher, P.A.; Colefax, A.P.; Coleman, M.A.; Curley, B.G.; Kelaher, B.P. Using drones to quantify beach users across a range of environmental conditions. J. Coast. Conserv. 2019, 23, 633-642. [CrossRef]

43. Giles, A.B.; Butcher, P.A.; Colefax, A.P.; Pagendam, D.E.; Kelaher, B.P. Responses of bottlenose dolphins (Tursiops spp.) to small drones. Aquat. Conserv. Mar. Freshw. Ecosyst. 2020, 1-8. [CrossRef]

44. Klimley, A.P.; Anderson, S.D.; Pyle, P.; Henderson, R.P. Spatiotemporal Patterns of White Shark (Carcharodon carcharias) Predation at the South Farallon Islands, California. Copeia 1992, 3, 680-690. [CrossRef]

45. Christiansen, F.; Rojano-Doñate, L.; Madsen, P.T.; Bejder, L. Noise Levels of Multi-Rotor Unmanned Aerial Vehicles with Implications for Potential Underwater Impacts on Marine Mammals. Front. Mar. Sci. 2016, 3, 277. [CrossRef]

46. Porter, M.E.; Ruddy, B.R.; Kajiura, S.M. Volitional Swimming Kinematics of Blacktip Sharks, Carcharhinus limbatus, in the Wild. Drones 2020, 4, 78. [CrossRef]

47. Kajiura, S.M.; Tellman, S.L. Quantification of massive seasonal aggregations of blacktip sharks (Carcharhinus limbatus) in southeast Florida. PLoS ONE 2016, 11, e0150911. [CrossRef] [PubMed]

48. Raoult, V.; Broadhurst, M.K.; Peddemors, V.M.; Williamson, J.E.; Gaston, T.F. Resource use of great hammerhead sharks (Sphyrna mokarran) off eastern Australia. J. Fish Biol. 2019, 95, 1430-1440. [CrossRef] [PubMed]

49. Tagliafico, A.; Butcher, P.A.; Colefax, A.P.; Clark, G.F.; Kelaher, B.P. Variation in cownose ray Rhinoptera neglecta abundance and group size on the central east coast of Australia. J. Fish Biol. 2020, 96, 427-433. [CrossRef] [PubMed]

50. Torney, C.J.; Lamont, M.; Debell, L.; Angohiatok, R.J.; Leclerc, L.-M.; Berdahl, A.M. Inferring the rules of social interaction in migrating caribou. Philos. Trans. R. Soc. B Biol. Sci. 2018, 373, 20170385. [CrossRef]

51. Harris, J.M.; Nelson, J.A.; Rieucau, G.; Broussard, W.P. Use of Drones in Fishery Science. Trans. Am. Fish. Soc. 2019, 148, 687-697. [CrossRef]

52. Spaet, J.L.Y.; Patterson, T.A.; Bradford, R.W.; Butcher, P.A. Spatiotemporal distribution patterns of immature Australasian white sharks (Carcharodon carcharias). Sci. Rep. 2020, 10, 10169. [CrossRef]

53. Curtis, T.H.; Kelly, J.; Menard, K.; Laroche, R.; Jones, R.; Klimley, A.P. Observations on the behavior of White Sharks scavenging from a Whale carcass at Point Reyes, California. Calif. Fish Game 2006, 92, 113-124.

54. Clua, E.; Chauvet, C.; Read, T.; Werry, J.M.; Lee, S.Y. Behavioural patterns of a Tiger Shark (Galeocerdo cuvier) feeding aggregation at a Blue Whale carcass in Prony Bay, New Caledonia. Mar. Freshw. Behav. Physiol. 2013, 46, 1-20. [CrossRef] 
55. Dicken, M. First observations of young of the year and juvenile Great White Sharks (Carcharodon carcharias) scavenging from a whale carcass. Mar. Freshw. Res. 2008, 59, 596-602. [CrossRef]

56. Tucker, J.P.; Santos, I.R.; Crocetti, S.; Butcher, P. Whale carcass strandings on beaches: Management challenges, research needs, and examples from Australia. Ocean Coast. Manag. 2018, 163, 323-338. [CrossRef]

57. Tucker, J.P.; Santos, I.R.; Davis, K.L.; Butcher, P.A. Whale carcass leachate plumes in beach groundwater: A potential shark attractant to the surf? Mar. Pollut. Bull. 2019, 140, 219-226. [CrossRef]

58. Fowler, S. The Conservation Status of Migratory Sharks; UNEP/CMS Secretariat: Bonn, Germany, 2014; 30p.

59. Gallagher, A.J.; Hammerschlag, N.; Danylchuk, A.J.; Cooke, S.J. Shark recreational fisheries: Status, challenges, and research needs. Ambio 2017, 46, 385-398. [CrossRef]

60. Fields, A.T.; Fischer, G.A.; Shea, S.K.H.; Zhang, H.; Abercrombie, D.L.; Feldheim, K.A.; Babcock, E.A.; Chapman, D.D. Species composition of the international shark fin trade assessed through a retail-market survey in Hong Kong. Conserv. Biol. 2018, 32, 376-389. [CrossRef]

61. Dent, F.; Clarke, S. State of the global market for shark products. In FAO Fisheries and Aquaculture Technical Paper No. 590; FAO: Rome, Italy, 2015; 187p.

62. Ferretti, F.; Myers, R.A.; Serena, F.; Lotze, H.K. Loss of large predatory sharks from the Mediterranean Sea. Conserv. Biol. 2008, 22, 952-964. [CrossRef] [PubMed]

63. Hayes, C.G.; Jiao, Y.; Cortés, E. Stock Assessment of Scalloped Hammerheads in the Western North Atlantic Ocean and Gulf of Mexico. North Am. J. Fish. Manag. 2009, 29, 1406-1417. [CrossRef]

64. Hutchings, J.A.; Myers, R.A.; García, V.B.; Lucifora, L.O.; Kuparinen, A. Life-history correlates of extinction risk and recovery potential. Ecol. Appl. 2012, 22, 1061-1067. [CrossRef]

65. Dulvy, N.K.; Baum, J.K.; Clarke, S.; Compagno, L.J.V.; Cortés, E.; Domingo, A.; Fordham, S.; Fowler, S.; Francis, M.P.; Gibson, C.; et al. You can swim but you can't hide: The global status and conservation of oceanic pelagic sharks and rays. Aquat. Conserv. Mar. Freshw. Ecosyst. 2008, 18, 459-482. [CrossRef]

66. Ketchum, J.T.; Galván-Magaña, F.; Klimley, A.P. Segregation and foraging ecology of whale sharks, Rhincodon typus, in the southwestern Gulf of California. Environ. Biol. Fishes 2013, 96, 779-795. [CrossRef]

67. Simpfendorfer, C.A.; Mildward, N.E. Utilisation of a tropical bay as a nursery area by sharks of the families Carcharhinidae and Sphyrnidae. Environ. Biol. Fishes 1993, 37, 337-345. [CrossRef]

68. Heupel, M.R.; Simpfendorfer, C.A. Quantitative analysis of aggregation behavior in juvenile blacktip sharks. Mar. Biol. 2005, 147, 1239-1249. [CrossRef]

69. Rowat, D.; Brooks, K.; March, A.; McCarten, C.; Jouannet, D.; Riley, L.; Jeffreys, G.; Perri, M.; Vely, M.; Pardigon, B. Long-term membership of whale sharks (Rhincodon typus) in coastal aggregations in Seychelles and Djibouti. Mar. Freshw. Res. 2011, 62, 621-627. [CrossRef]

70. Nalesso, E.; Hearn, A.; Sosa-Nishizaki, O.; Steiner, T.; Antoniou, A.; Reid, A.; Bessudo, S.; Soler, G.; Klimley, P.; Lara, F.; et al. Movements of scalloped hammerhead sharks (Sphyrna lewini) at Cocos Island, Costa Rica and between oceanic islands in the Eastern Tropical Pacific. PLoS ONE 2019, 14, e0213741. [CrossRef]

71. Mucientes, G.R.; Queiroz, N.; Sousa, L.L.; Tarroso, P.; Sims, D.W. Sexual segregation of pelagic sharks and the potential threat from fisheries. Biol. Lett. 2009, 5, 156-159. [CrossRef]

72. Clarke, S.C.; McAllister, M.K.; Milner-Gulland, E.J.; Kirkwood, G.P.; Michielsens, C.G.J.; Agnew, D.J.; Pikitch, E.K.; Nakano, H.; Shivji, M.S. Global estimates of shark catches using trade records from commercial markets. Ecol. Lett. 2006, 9, 1115-1126. [CrossRef]

73. Graham, F.; Rynne, P.; Estevanez, M.; Luo, J.; Ault, J.S.; Hammerschlag, N. Use of marine protected areas and exclusive economic zones in the subtropical western North Atlantic Ocean by large highly mobile sharks. Divers. Distrib. 2016, 22, 534-546. [CrossRef]

74. Queiroz, N.; Humphries, N.E.; Mucientes, G.; Hammerschlag, N.; Lima, F.P.; Scales, K.L.; Miller, P.I.; Sousa, L.L.; Seabra, R.; Sims, D.W. Ocean-wide tracking of pelagic sharks reveals extent of overlap with longline fishing hotspots. Proc. Natl. Acad. Sci. USA 2016, 113, 1582-1587. [CrossRef]

75. Compagno, L.J.V. Sharks of the World; Princeton University Press: Princeton, NJ, USA, 2005.

76. Gallagher, A.J.; Klimley, A.P. The biology and conservation status of the large hammerhead shark complex: The great, scalloped, and smooth hammerheads. Rev. Fish Biol. Fish. 2018, 28, 777-794. [CrossRef]

77. Bessudo, S.; Soler, G.A.; Klimley, P.A.; Ketchum, J.; Arauz, R.; Hearn, A.; Guzmán, A.; Calmettes, B. Vertical and horizontal movements of the scalloped hammerhead shark (Sphyrna lewini) round Malpelo and Cocos Islands (Tropical Eastern Pacific) using satellite telemetry. Bull. Mar. Coast. Res. 2011, 40, 91-106.

78. Hammerschlag, N.; Gallagher, A.J.; Lazarre, D.M.; Slonim, C. Range extension of the endangered great hammerhead shark Sphyrna mokarran in the Northwest Atlantic: Preliminary data and significance for conservation. Endanger. Species Res. 2011, 13, 111-116. [CrossRef]

79. Santos, C.; Coehlo, R. Migrations and habitat use of the smooth hammerhead shark (Sphyrna zygaena) in the Atlantic Ocean. PLoS ONE 2018, 13, e0198664. [CrossRef]

80. Roemer, R.P.; Gallagher, A.J.; Hammerschlag, N. Shallow water tidal flat use and associated specialized foraging behavior of the great hammerhead shark (Sphyrna mokarran). Mar. Freshw. Behav. Physiol. 2016, 49, 235-249. [CrossRef] 
81. Hearn, A.; Ketchum, J.; Klimley, A.P.; Espinoza, E.; Peñaherrera, C. Hotspots within hotspots? Hammerhead shark movements around Wolf Island, Galapagos Marine Reserve. Mar. Biol. 2010, 157, 1899-1915. [CrossRef] [PubMed]

82. Francis, M.P. Distribution, habitat and movement of juvenile smooth hammerhead sharks (Sphyrna zygaena) in northern New Zealand. N. Z. J. Mar. Freshw. Res. 2016, 50, 506-525. [CrossRef]

83. Brown, K.T.; Seeto, J.; Lal, M.M.; Miller, C.E. Discovery of an important aggregation area for endangered scalloped hammerhead sharks, Sphyrna lewini, in the Rewa River estuary, Fiji Islands. Pac. Conserv. Biol. 2016, 22, 242-248. [CrossRef]

84. Duncan, K.M.; Holland, K.N. Habitat use, growth rates and dispersal patterns of juvenile scalloped hammerhead sharks Sphyrna lewini in a nursery habitat. Mar. Ecol. Prog. Ser. 2006, 312, 211-221. [CrossRef]

85. Jennings, R.D. Seasonal abundance of hammerhead sharks off Cape Canaveral, Florida. Copeia 1985, 223-225. [CrossRef]

86. Kenney, R.D.; Owen, R.E.; Winn, H.E. Shark distributions off the Northeast United States from Marine Mammal Surveys. Copeia 1985, 1985, 220-223. [CrossRef]

87. Dicken, M.L.; Booth, A.J. Surveys of white sharks (Carcharodon carcharias) off bathing beaches in Algoa Bay, South Africa. Mar. Freshw. Res. 2013, 64, 530-539. [CrossRef]

88. Laran, S.; Authier, M.; Van Canneyt, O.; Dorémus, G.; Watremez, P.; Ridoux, V. A comprehensive survey of pelagic megafauna: Their distribution, densities, and taxonomic richness in the tropical Southwest Indian ocean. Front. Mar. Sci. 2017, 4, 139. [CrossRef]

89. Ducatez, S. Which sharks attract research? Analyses of the distribution of research effort in sharks reveal significant non-random knowledge biases. Rev. Fish Biol. Fish. 2019, 29, 355-367. [CrossRef]

90. Osgood, G.; Baum, J. Reef sharks: Recent advances in ecological understanding to inform conservation. J. Fish Biol. 2015, 87, 1489-1523. [CrossRef] [PubMed]

91. Heupel, M.; Simpfendorfer, C. Using acoustic monitoring to evaluate MPAs for shark nursery areas: The importance of long-term data. Mar. Technol. Soc. J. 2005, 39, 10-18. [CrossRef]

92. Heupel, M.R.; Lédée, E.J.; Simpfendorfer, C.A. Telemetry reveals spatial separation of co-occurring reef sharks. Mar. Ecol. Prog. Ser. 2018, 589, 179-192. [CrossRef]

93. Cagua, E.F.; Berumen, M.L.; Tyler, E. Topography and biological noise determine acoustic detectability on coral reefs. Coral Reefs 2013, 32, 1123-1134. [CrossRef]

94. Whitmarsh, S.K.; Fairweather, P.G.; Huveneers, C. What is Big BRUVver up to? Methods and uses of baited underwater video. Rev. Fish Biol. Fish. 2017, 27, 53-73. [CrossRef]

95. Barker, S.M.; Peddemors, V.M.; Williamson, J.E. A video and photographic study of aggregation, swimming and respiratory behaviour changes in the Grey Nurse Shark (Carcharias taurus) in response to the presence of SCUBA divers. Mar. Freshw. Behav. Physiol. 2011, 44, 75-92. [CrossRef]

96. Smith, K.; Scarr, M.; Scarpaci, C. Grey nurse shark (Carcharias taurus) diving tourism: Tourist compliance and shark behaviour at Fish Rock, Australia. Environ. Manag. 2010, 46, 699-710. [CrossRef]

97. Joyce, K.; Duce, S.; Leahy, S.; Leon, J.X.; Maier, S. Principles and practice of acquiring drone based image data in marine environments. Mar. Freshw. Res. 2018, 70, 952-963. [CrossRef]

98. Carlisle, A.B.; Starr, R.M. Habitat use, residency, and seasonal distribution of female leopard sharks Triakis semifasciata in Elkhorn Slough, California. Mar. Ecol. Prog. Ser. 2009, 380, 213-228. [CrossRef]

99. Nakano, H.; Matsunaga, H.; Okamoto, H.; Okazaki, M. Acoustic tracking of bigeye thresher shark Alopias superciliosus in the eastern Pacific Ocean. Mar. Ecol. Prog. Ser. 2003, 265, 255-261. [CrossRef]

100. Kessel, S.T.; Gruber, S.; Gledhill, K.; Bond, M.; Perkins, R.G. Aerial survey as a tool to estimate abundance and describe distribution of a carcharhinid species, the lemon shark, Negaprion brevirostris. J. Mar. Biol. 2013, 2013, 1-10. [CrossRef]

101. Bennett, M.K.; Younes, N.; Joyce, K. Automating Drone Image Processing to Map Coral Reef Substrates Using Google Earth Engine. Drones 2020, 4, 50. [CrossRef]

102. Casella, E.; Collin, A.; Harris, D.; Ferse, S.; Bejarano, S.; Parravicini, V.; Hench, J.L.; Rovere, A. Mapping coral reefs using consumer-grade drones and structure from motion photogrammetry techniques. Coral Reefs 2017, 36, 269-275. [CrossRef]

103. Kabiri, K.; Rezai, H.; Moradi, M. A drone-based method for mapping the coral reefs in the shallow coastal waters-case study: Kish Island, Persian gulf. Earth Sci. Inform. 2020, 13, 1265-1274. [CrossRef]

104. Chabot, D. Trends in drone research and applications as the Journal of Unmanned Vehicle Systems turns five. J. Unmanned Veh. Syst. 2018, 6, vi-xv. [CrossRef]

105. Hardin, P.J.; Lulla, V.; Jensen, R.R.; Jensen, J.R. Small Unmanned Aerial Systems (sUAS) for environmental remote sensing: Challenges and opportunities revisited. GISci. Remote Sens. 2018, 56, 309-322. [CrossRef]

106. Johnston, D.W. Unoccupied aircraft systems in marine science and conservation. Annu. Rev. Mar. Sci. 2019, 11, 439-463. [CrossRef]

107. Letnes, P.A.; Hansen, I.M.; Aas, L.M.S.; Eide, I.; Pettersen, R.; Tassara, L.; Receveur, J.; le Floch, S.; Guyomarch, J.; Camus, L.; et al. Underwater hyperspectral classification of deep sea corals exposed to 2-methylnaphthalene. PLoS ONE 2019, 14, e0209960. [CrossRef]

108. Chennu, A.; Farber, P.; De'ath, G.; de Beer, D.; Fabricius, K.E. A diver-operated hyperspectral imaging and topographic surveying system for automated mapping of benthic habitats. Sci. Rep. 2017, 7, 7122. [CrossRef] 
109. Colefax, A. Developing the Use of Drones for Non-Destructive Shark Management and Beach Safety. Ph.D. Thesis, Southern Cross University, Lismore, Australia, 2020.

110. Hodgson, J.C.; Baylis, S.M.; Mott, R.; Herrod, A.; Clarke, R.H. Precision wildlife monitoring using unmanned aerial vehicles. Sci. Rep. 2016, 6, 22574. [CrossRef]

111. Pope, R.M.; Fry, E.S. Absorption spectrum $(380-700 \mathrm{~nm})$ of pure water. II. Integrating cavity measurements. Appl. Opt. 1997, 36, 8710-8723. [CrossRef] [PubMed]

112. Seymour, A.C.; Dale, J.; Hammill, M.; Halpin, P.N.; Johnston, D.W. Automated detection and enumeration of marine wildlife using unmanned aircraft systems (UAS) and thermal imagery. Sci. Rep. 2017, 7, 45127. [CrossRef] [PubMed]

113. Spaan, D.; Burke, C.; McAree, O.; Aureli, F.; Rangel-Rivera, C.E.; Hutschenreiter, A.; Longmore, S.N.; McWhirter, P.R.; Wich, S.A. Thermal Infrared Imaging from Drones Offers a Major Advance for Spider Monkey Surveys. Drones 2019, 3, 34. [CrossRef]

114. Horton, T.W.; Hauser, N.; Cassel, S.; Klaus, K.F.; Fettermann, T.; Key, N. Doctor Drone: Non-invasive Measurement of Humpback Whale Vital Signs Using Unoccupied Aerial System Infrared Thermography. Front. Mar. Sci. 2019, 6, 466. [CrossRef]

115. Thomas, G.L.; Thorne, R.E. Night-time predation by Steller sea lions. Nature 2001, 411, 1013. [CrossRef] [PubMed]

116. Schoonmaker, J.S.; Podobna, Y.; Boucher, C.D. Electro-optical approach for airborne marine mammal surveys and density estimations. U.S. Navy J. Underw. Acoust. 2011, 61, 668-985.

117. Blount, C.; Schoonmaker, J.; Saggese, S.; Oakley, D. An Innovative Method for Obtaining High Detection Rates of Sharks on Ocean Beaches; A Report for Shark Alert Pty Ltd.; Cardno: Sydney, NSW, Australia, 2016; 35p.

118. Fretwell, P.T.; Staniland, I.J.; Forcada, J. Whales from space: Counting southern right whales by satellite. PLoS ONE 2014, 9 , e88655. [CrossRef]

119. Parsons, M.; Bratanov, D.; Gaston, K.J.; Gonzalez, F. UAVs, Hyperspectral Remote Sensing, and Machine Learning Revolutionizing Reef Monitoring. Sensors 2018, 18, 2026. [CrossRef]

120. Burke, C.; Rashman, M.F.; McAree, O.; Hambrecht, L.; Longmore, S.N.; Piel, A.K.; Wich, S.A. Addressing environmental and atmospheric challenges for capturing high-precision thermal infrared data in the field of astro-ecology. In Proceedings Volume 10709, High Energy, Optical, and Infrared Detectors for Astronomy VIII; SPIE Astronomical Telescopes + Instrumentation: Austin, TX, USA, 2018.

121. Hambrecht, L.; Brown, R.P.C.; Piel, A.K.; Wich, S.A. Detecting 'poachers' with drones: Factors influencing the probability of detection with TIR and RGB imaging in miombo woodlands, Tanzania. Biol. Conserv. 2019, 233, 109-117. [CrossRef]

122. Hodgson, J.; Mott, R.; Baylis, S.; Pham, T.; Wotherspoon, S.; Kilpatrick, A.; Raja Segaran, R.; Reid, I.; Terauds, A.; Koh, L. Drones count wildlife more accurately and precisely than humans. Methods Ecol. Evol. 2018, 9, 1160-1167. [CrossRef]

123. Burr, P.; Samiappan, S.; Hathcock, L.; Moorhead, R.; Dorr, B. Estimating waterbird abundance on catfish aquaculture ponds using an unmanned aerial system. Hum. Wildl. Interact. 2019, 13. [CrossRef]

124. Eikelboom, J.; Wind, J.; Ven, E.; Kenana, M.; Schroder, B.; Knegt, H.; Langevelde, F.; Prins, H. Improving the precision and accuracy of animal population estimates with aerial image object detection. Methods Ecol. Evol. 2019, 10, 1875-1887. [CrossRef]

125. Sandino, J.; Gonzalez, F. A novel approach for invasive weeds and vegetation surveys using UAS and Artificial Intelligence. In Proceedings of the 2018 23rd International Conference on Methods Models in Automation Robotics (MMAR), Międzyzdroje, Poland, 27-30 August 2018; pp. 515-520.

126. Nevalainen, O.; Honkavaara, E.; Tuominen, S.; Viljanen, N.; Hakala, T.; Yu, X.; Hyyppä, J.; Saari, H.; Pölönen, I.; Imai, N.; et al Individual tree detection and classification with UAV-based photogrammetric point clouds and hyperspectral imaging. Remote Sens. 2017, 9, 185. [CrossRef]

127. Sandino, J.; Pegg, G.; Gonzalez, F.; Smith, G. Aerial Mapping of forests affected by pathogens using UAVs, hyperspectral sensors, and artificial intelligence. Sensors 2018, 18, 944. [CrossRef] [PubMed]

128. Geraeds, M.; van Emmerik, T.; de Vries, R.; Ab Razak, M.S. Riverine plastic litter monitoring using unmanned aerial vehicles (UAVs). Remote Sens. 2019, 11, 2045. [CrossRef]

129. Dujon, A.; Schofield, G. Importance of machine learning for enhancing ecological studies using information-rich imagery. Endanger. Species Res. 2019, 39, 91-104. [CrossRef]

130. Maire, F.; Alvarez, L.M.; Hodgson, A. Automating marine mammal detection in aerial images captured during wildlife surveys: A deep learning approach. In AI 2015: Advances in Artificial Intelligence; Pfahringer, B., Renz, J., Eds.; Springer International Publishing: Cham, Switzerland, 2015; pp. 379-385.

131. Dharmawan, W.; Nambo, H. End-to-End Xception model implementation on Carla Self Driving Car in moderate dense environment. In Proceedings of the 2019 2nd Artificial Intelligence and Cloud Computing Conference, AICCC 2019, Kobe, Japan, 21-23 December 2019; Association for Computing Machinery: New York, NY, USA, 2019; pp. 139-143.

132. Sanil, N.; Rakesh, V.; Mallapur, R.; Ahmed, M.R. Deep learning techniques for obstacle detection and avoidance in driverless cars. In Proceedings of the 2020 International Conference on Artificial Intelligence and Signal Processing (AISP), Vellore, India, 10-12 January 2020; pp. 1-4.

133. Ismail, W.N.; Hassan, M.M.; Alsalamah, H.A.; Fortino, G. CNN-Based health model for regular health factors analysis in internet-of-medical things environment. IEEE Access 2020, 8, 52541-52549. [CrossRef]

134. Ditria, E.M.; Lopez-Marcano, S.; Sievers, M.; Jinks, E.L.; Brown, C.J.; Connolly, R.M. Automating the analysis of fish abundance using object detection: Optimizing animal ecology with deep learning. Front. Mar. Sci. 2020, 7, 429. [CrossRef] 
135. Fernandes, A.F.; Turra, E.M.; de Alvarenga, É.R.; Passafaro, T.L.; Lopes, F.B.; Alves, G.F.; Singh, V.; Rosa, G.J. Deep Learning image segmentation for extraction of fish body measurements and prediction of body weight and carcass traits in Nile tilapia. Comput. Electron. Agric. 2020, 170, 105274. [CrossRef]

136. Hughes, B.; Burghardt, T. Automated visual fin identification of individual great white sharks. Int. J. Comput. Vis. 2017, $122,542$. [CrossRef]

137. Gonda, F.; Kaynig, V.; Jones, T.R.; Haehn, D.; Lichtman, J.W.; Parag, T.; Pfister, H. ICON: An Interactive Approach to Train Deep Neural Networks for Segmentation of Neuronal Structures. In Proceedings of the 2017 IEEE 14th International Symposium on Biomedical Imaging (ISBI 2017), Melbourne, Australia, 18-21 April 2017; pp. 327-331.

138. Smith, A.G.; Han, E.; Petersen, J.; Olsen, N.A.F.; Giese, C.; Athmann, M.; Dresbøll, D.B.; Thorup-Kristensen, K. RootPainter: Deep learning segmentation of biological images with corrective annotation. bioRxiv 2020. [CrossRef]

139. Kellenberger, B.; Marcos, D.; Lobry, S.; Tuia, D. Half a percent of labels is enough: Efficient animal detection in UAV imagery using deep CNNs and active learning. IEEE Trans. Geosci. Remote Sens. 2019, 57, 9524-9533. [CrossRef]

140. Chirayath, V.; Li, A. Next-Generation optical sensing technologies for exploring ocean worlds-NASA FluidCam, MiDAR, and NeMO-Net. Front. Mar. Sci. 2019, 6, 521. [CrossRef]

141. Gray, P.C.; Bierlich, K.C.; Mantell, S.A.; Friedlaender, A.S.; Goldbogen, J.A.; Johnston, D.W. Drones and convolutional neural networks facilitate automated and accurate cetacean species identification and photogrammetry. Methods Ecol. Evol. 2019, 10, 1490-1500. [CrossRef]

142. Lowe, C.G.; White, C.F.; Clark, C.M. Use of autonomous vehicles for tracking and surveying of acoustically tagged elasmobranchs. In Shark Research: Emerging Technologies and Applications for the Field and Laboratory; Carrier, J., Heithaus, M., Simpfendorfer, C., Eds.; CRC Press: Boca Raton, FL, USA, 2018.

143. Eiler, J.H.; Grothues, T.M.; Dobarro, J.A.; Masuda, M.M. Comparing autonomous underwater vehicle (AUV) and vessel-based tracking performance for locating acoustically tagged fish. Mar. Fish. Rev. 2013, 75, 27-42. [CrossRef]

144. Goudey, C.A.; Consi, T.; Manley, J.; Graham, M.; Donovan, B.; Kiley, L. A robotic boat for autonomous fish tracking. Mar. Technol. Soc. J. 1998, 32, 47.

145. Grothues, T.; Dobarro, J.; Eiler, J. Collecting, interpreting, and merging fish telemetry data from an AUV: Remote sensing from an already remote platform. In Proceedings of the 2010 Autonomous Underwater Vehicles Symposium, Monterey, CA, USA, 1-3 September 2010; Volume 136, pp. 1-9.

146. Grothues, T.; Dobarro, J.; Ladd, J.; Higgs, A.; Niezgoda, G.; Miller, D. Use of a multi-sensored AUV to telemeter tagged Atlantic sturgeon and map their spawning habitat in the Hudson River, USA. In Proceedings of the 2008 Autonomous Underwater Vehicles Symposium, Woods Hole, MA, USA, 13-14 October 2008; pp. 1-7.

147. Raoult, V.; Williamson, J.E.; Smith, T.M.; Gaston, T.F. Effects of on-deck holding conditions and air exposure on post-release behaviours of sharks revealed by a remote operated vehicle. J. Exp. Mar. Biol. Ecol. 2019, 511, 10-18. [CrossRef]

148. White, C.F.; Lin, Y.; Clark, C.M.; Lowe, C.G. Human vs robot: Comparing the viability and utility of autonomous underwater vehicles for the acoustic telemetry tracking of marine organisms. J. Exp. Mar. Biol. Ecol. 2016, 485, 112-118. [CrossRef]

149. Raoult, V.; Colefax, A.P.; Allan, B.M.; Cagnazzi, D.; Castelblanco-Martínez, N.; Ierodiaconou, D.; Johnston, D.W.; Landeo-Yauri, S.; Lyons, M.; Pirotta, V.; et al. Operational protocols for the Use of Drones in Marine Animal Research. J. Drones $2020,4,64$. [CrossRef] 